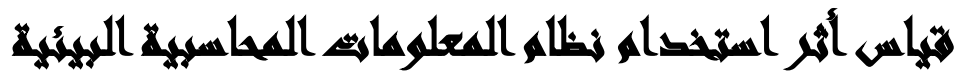

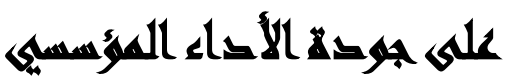

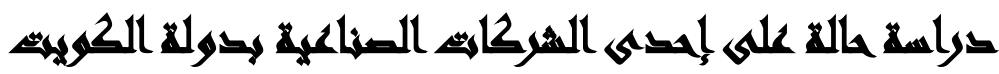

\section{[1 $\leqslant]$}

جمـال سعد خطاب(')-- محمد عبد العزيز خليفة(')- راثد شبيب العجمي(؟)

حمد ماجد حمد الإند

() كلية التجارة، جامعة عين شمس r) كلية العلوم الادارية، جامعة الكويت

\section{المستحلصن}

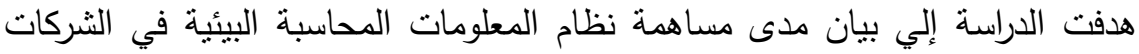

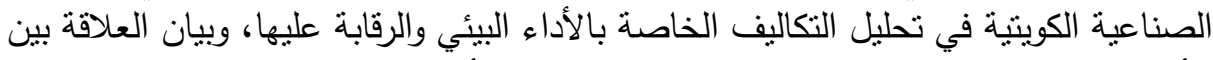

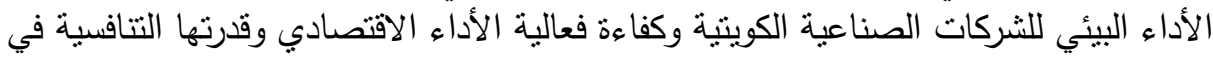

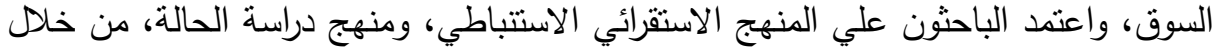
تصميم قائمة استقصاء تخص المحاسبين والمراجعين والمدراء الماليين في شركة الإسئ السمنت

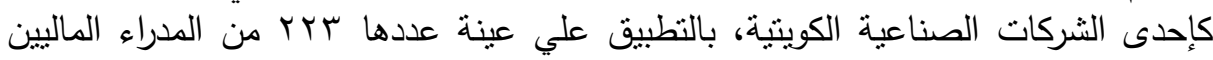

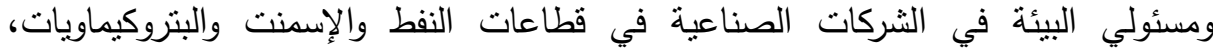

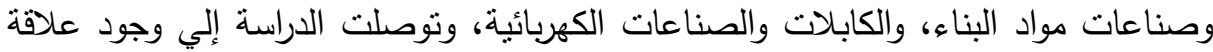

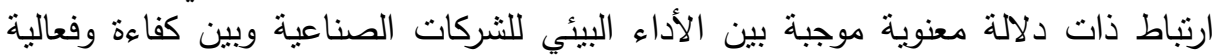

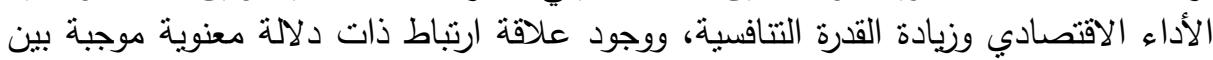

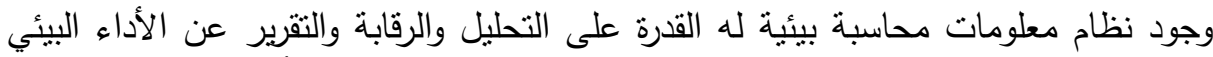

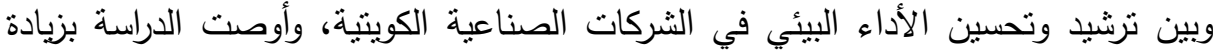

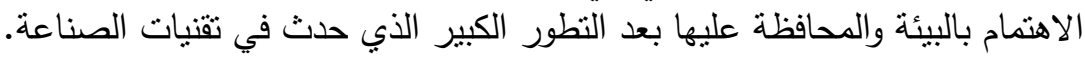

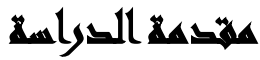

لقد أصبح من الضروري إيجاد طرق لقياس الآثار البيئية ومعالجتها محاسبياً والإبلاغ

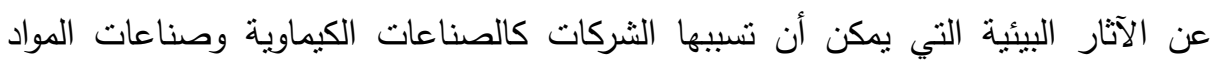

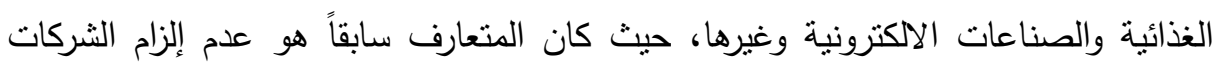
بتحميل تكلفة التلوث والإجراءات الوقائية كما يحدث اليوم من متطلبات اجتماعية امتدت إلى إنى

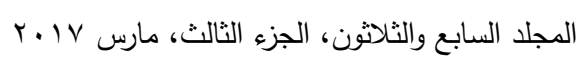


المسئولين لمساءلة المنشآت عن التلوث في البيئة الذي تسببه، ولما كانت عملية الحفاظ على

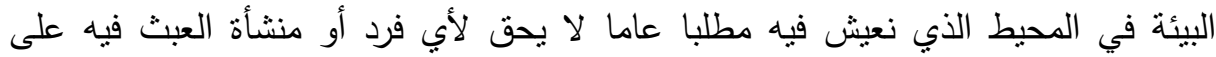

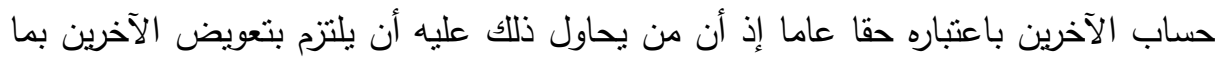

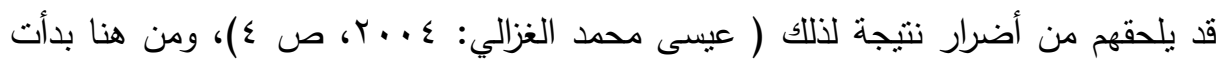

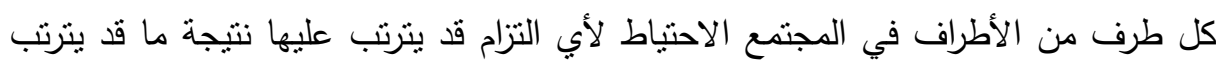

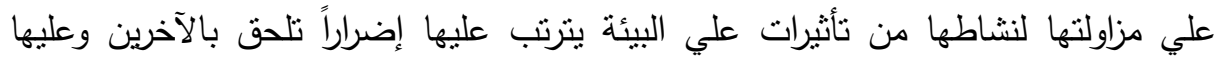

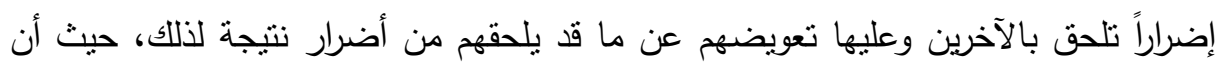

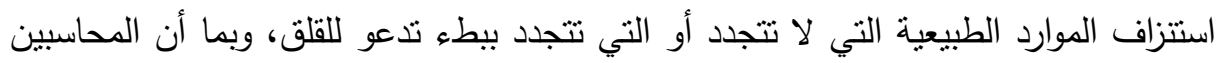

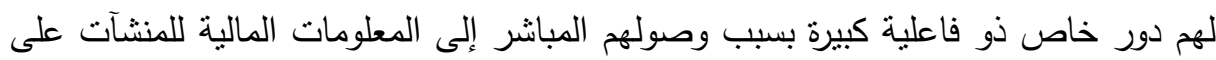
اختلافها وقدرتهم على تحسين أو التحقق من نوعية المعلومات ومهاراتهم في استخدام

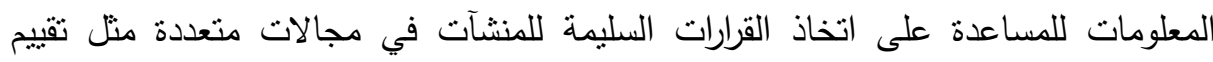
الاستثمار فعليهم يقع العبء الأكبر في القياس والإفصاح والإبلاغ عن المعلومات المحاسبية البيئية، ولقد أدركت الجهات المعنية بالبيانات الحسابات الختامية والتقارير المالية أهمية اللجوء إلى المحاسبة البيئية والتكاليف البيئية والاهتمام بالتقارير البيئية إلى أن بادر فريق الخبراء

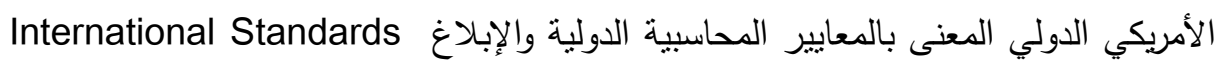
أحد الهيئات المنبثقة عن مؤتمر الأمم المتحدة (ISAR)OF Accounting OF Reporting للتجارة والتتمية (UNCTAD) بإصدار دليل يظهر كيفية معالجة الالتزامات التي قد يتزتب على أي طرف من الأطراف خلال مزاولته لنشاطه ومهنته العبث بالبيئة وإلحاق الضرر

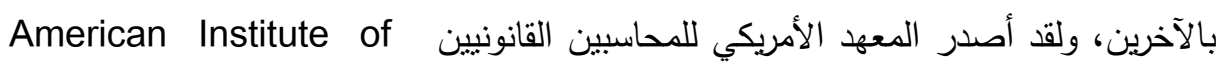
(AICPA)Certified Public Accountants

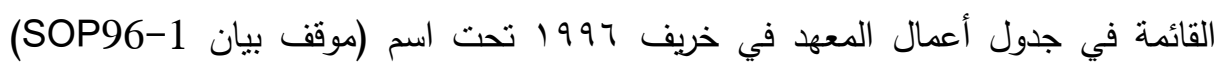
وهذه القائمة تعطي إرشاداً مفيداً ومفصلاً بشأن معالجة التكاليف البيئية والالتزامات البيئية

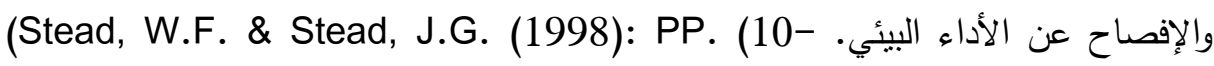


ولقد تزايد في الفترة الأخيرة احتباجات ومنطلبات مستخدمي القوائم المالية والتقارير

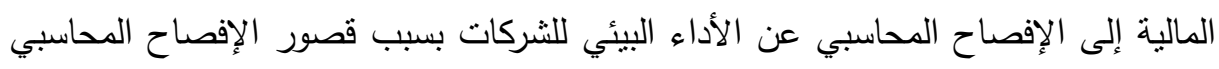

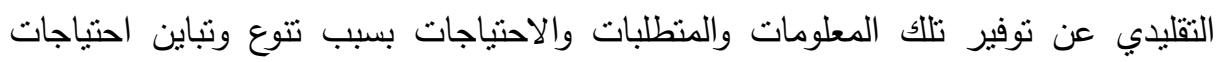
المستثمرين لتعدد البدائل المتاحة أمامهم واحتياجهم لتقييم كل بديل في ضوفي ضوه النشاط الاقتصادي والبيئي للشركة مما جعل الجمعيات والهيئات العلمية المتخصصة في مجال المحاسبة نطالب بالإفصاح عن الالتزامات البيئية في القوائم المالية، وذلك من خلادئي نظات محاسبي بيئي متخصص يعمل على نوفير المعلومات المالية وغير المالية المتعلقة بالآثار البيئية لتساعد مستخدمي القوائم المالية في نرشيد قراراتهم للتأكد من وفاء الثركات بمسئولياتها

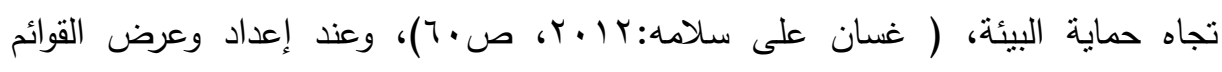

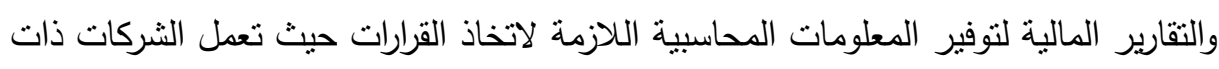
الأضرار البيئية على إزالة تلك الأضرار من خلال إنفاق مبالغ مالية أو تحمل التزامات بيئية

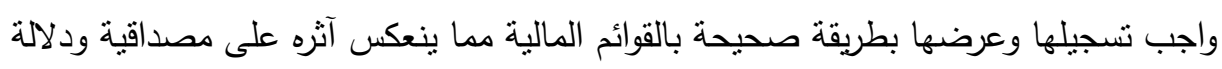
القوائم والتقارير المالية والإيضاحات المتممة لها.

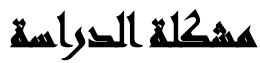

نتيجة إصدار القانون رقم (؟) لسنة ؟99 ألمصري ولائحته التتفيذية وقانون حماية

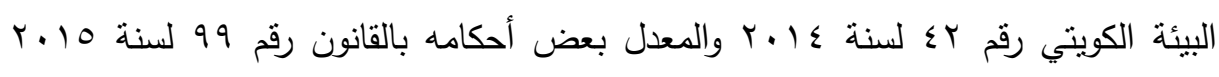

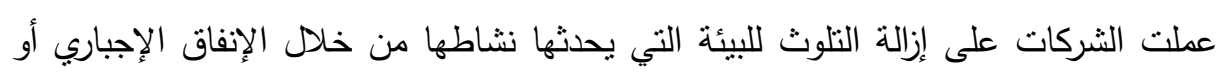

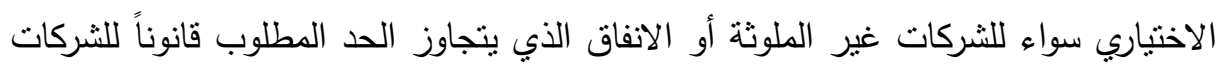

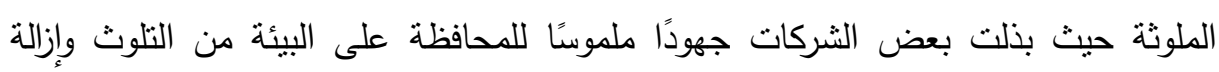
تأثنيراتها ولكن تلاحظ ما يلي: أني - أنه لم يستدل على تلك التكاليف عند إعداد وتصوير القوائم المالية متمنتة في التكاليف والالنزامات البيئية في بنود تقصيلية. 
- كما أن الإيضاحات المتممة والتي تعتبر جزءًا لا يتجزأ من القوائم المالية لم توضح تفصيلاً كيفية قياس ومعالجة تلك التكاليف البيئية ولم توضح اين أدرجت تلإنك القيم ضمن المحتوي الإخباري للقوائم المالية. - لم ينم الاستدلال على انعكاسات نلك التكاليف البيئية في السجلات المحاسبية وذللك لعدم وجود سجلات للنلوث البيئي ضمن النظام المحاسبي ودورته المستندية والدفترية.

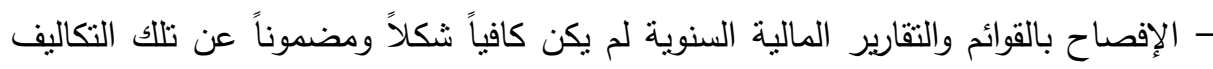
البيئية عند عرض الالنزامات البيئية المؤكدة أو المحتملة.

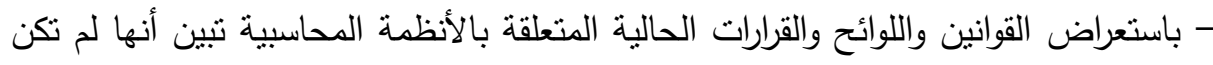
كافية لنؤدي دورها في التحقق من مدي التزام تلك الثركات بحماية البيئة وذللك لعدم

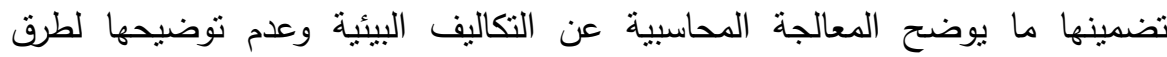
الإفصاح عن تللك التكاليف بالقوائم المالية والإيضاحات المتممة لها. - القصور في الإفصاح عن التكاليف البيئية يؤثر على قرار الاستثمار خلال دفع المستثمر

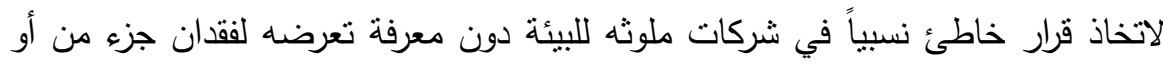

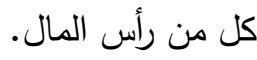
وعلي ضوء هذا الاهتمام المتزايد من قبل المستثرين للتعرف علي التأثيرات البيئية التي

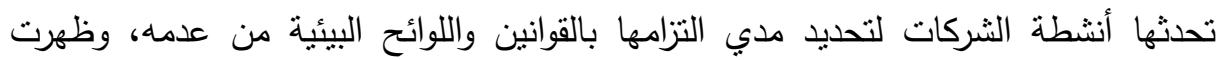
الحاجة إلي التعرف على التكاليف البيئية التى تتحملها كل شركة، ومع قصور موقف المعايير المحاسبية المصرية تجاه هذه المشكلة لعدم أخذها موقفا من هذه التغيرات أو كيفية معالجة التكاليف البيئية اتجهت الثركات إلي انتهاج طرق ومناهج مختلفة لقياس ومعالجة التكاليف كما امتد ذلك لطرق الإفصاح عنها فهنالك شركات تتفق إنفاق بيئي ولا تفصح عنه مما نتج عنه عدم مقدرة مستخدمي القوائم المالية الوقوف بشفافية ووضوح على موقف هذه الثركات تجاه الإنفاق البيئي.

وهدفت دراسة: -عبد البر الي التحقق من وجود معايير محاسبية متعلقة بالإفصاح

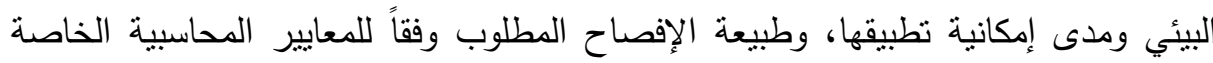

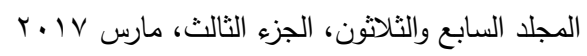


بالإفصاح البيئي من واقع التجارب لبعض الثركات الصناعية المنتشرة في دول عديدة وفى

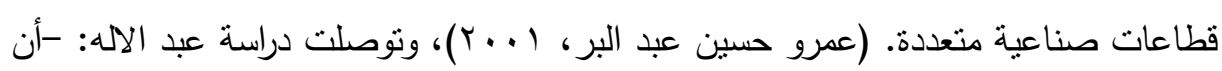
أفضل مدخل للقياس هو المدخل الكمي للأنشطة الفعلية، وأن نطبيق المحاسبة البيئية في الثركات الصناعية يؤثر بشكل ايجابي على اقتصاديات تلك المشاريع في المدى البعيد.

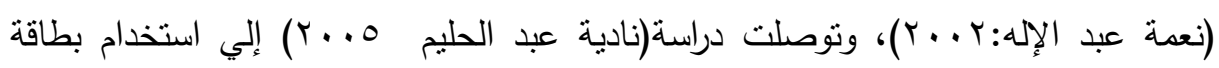

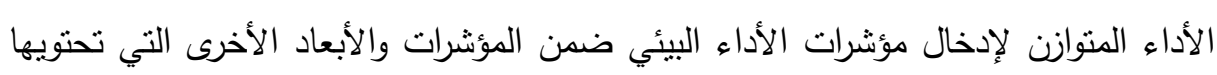

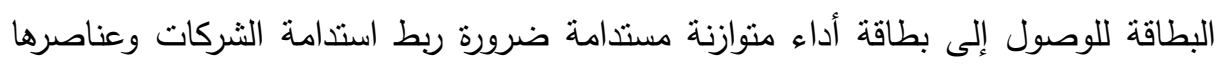

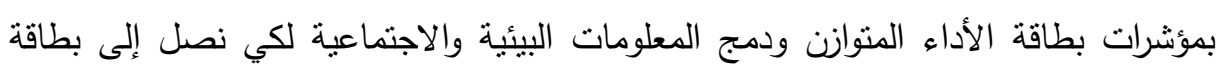

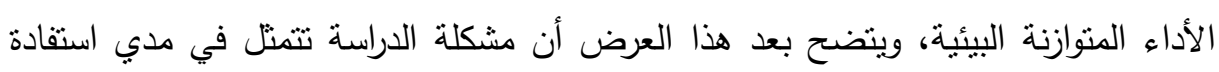

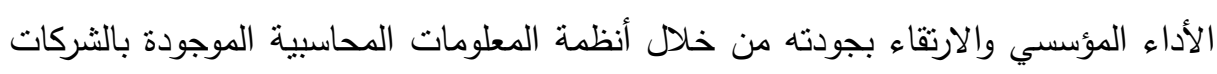
الصناعية، وأثز تلك الأنظمة في جودة الأداء المؤسسي.

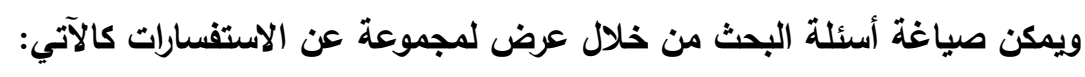
- إلى أي مدي يساعد نظام معلومات المحاسبة البيئية المطبقة في الشركات الصناعن الصناعية

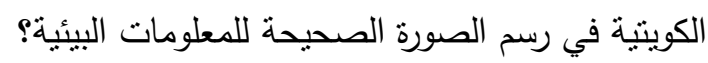
- ما أوجه القصور التي تواجهها الثركات؟ ماتج - ما العلاقة بين تحسن الأداء البيئي للشركات الصناعية الكويتية وكفاءة أداءها الاقتصادي لئهي

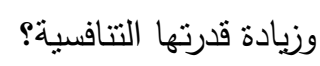
- ما العلاقة بين التحليل، الرقابة، التقرير عن الأداء البيئي وتحسين الأداء البيئي للشركات الصناعية الكويتية؟ مانه

- ما المقصود بالأداء المؤسسي وما هي معايير الجودة؟

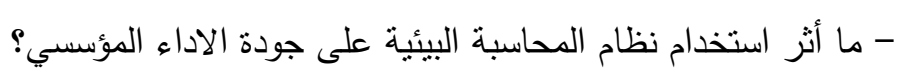




\section{مسطلحائ التراسما}

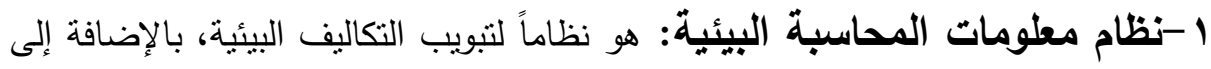

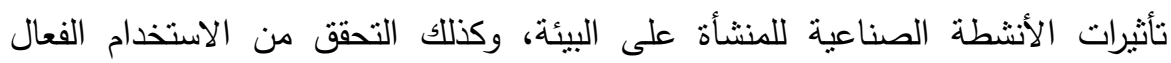

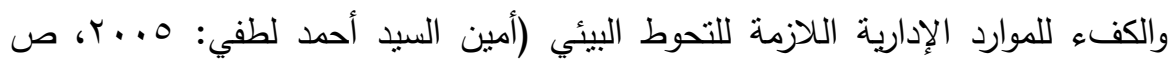

Y-مفهوم الأداء المؤسسي: يتناول ثلاثة مستويات فيشير المستوى الأول منها إلى أداء

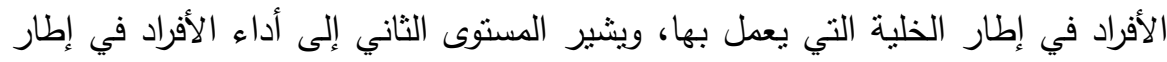

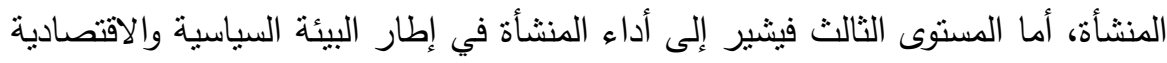

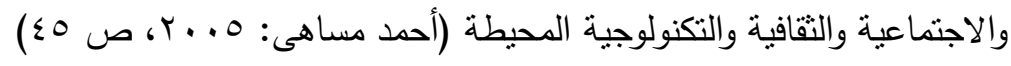

\section{أهساهيم الترواسلة}

\section{يسعى الباحثون من خلال ذلك البحث لتحقيق الأهداف الآتية:}

- تحديد منفعة المعلومات التي يوفرها نظام معلومات الححاسبة البيئية الدطبق في الثركات الصناعية الكوينية.

- بيان أوجه القصور في المعلومات التي يوفرها نظام معلومات المحاسبة البيئية المطبق في

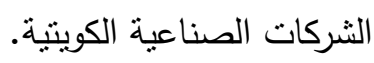

- بيان مدى مساهمة نظام المعلومات المحاسبة البيئية في الثركات الصناعية الكويتية في تحليل التكاليف الخاصة بالأداء البيئي والرقابة عليها. - بيان العلاقة بين الأداء البيئي للشركات الصناعية الكوينية وكفاءة فعالية الأداء الاقتصادي

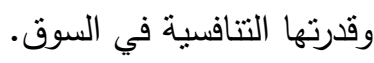




\section{هروخ التوراسة}

الفرض الأول: "لا نوجد علاقة ارتباط ذات دلالة بين تحسن الأداء البيئي للشركات الصناعية الكويتية وكفاءة وفعالية أداءها الاقتصادي وزيادة قدرتها التنافسية". الفرض الثاني: "لا توجد علاقة ارتباط ذات دلالة بين وجود نظام معلومات محاسبة بيئة له القدرة على التحليل والرقابة والنقرير عن الأداء البيئي وترشيد وتحسين الأداء البئئي في البئي

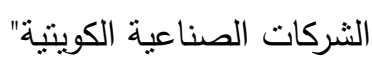
الفرض الثالث: "لا توجد مشكلات في القياس والإفصاح عن الأعباء البيئية".

\section{أهمية التواسمة}

تثتمل أهمية الدراسة على:

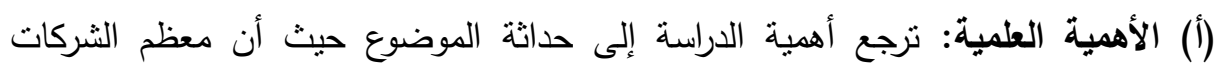

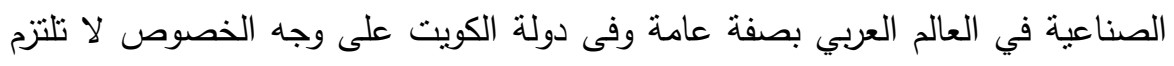

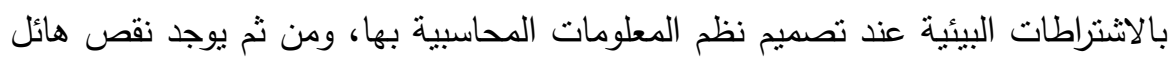

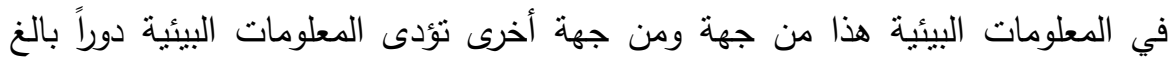

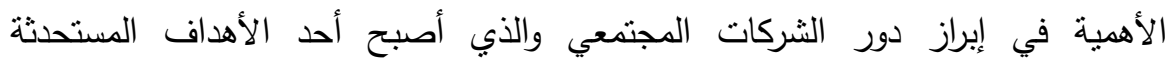

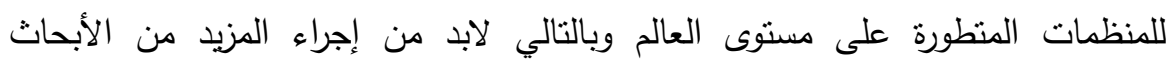

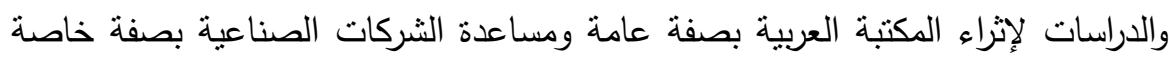

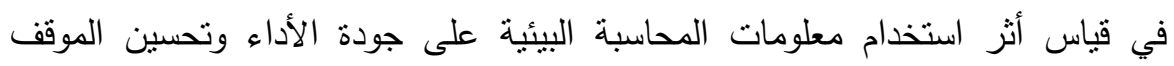
التنافسي لنتلك الثركات.

(ب) الأهمية العملية: بعتبر الاهتمام بالمعلومات البيئية الني يوفرها نظام الححاسبة البيئية

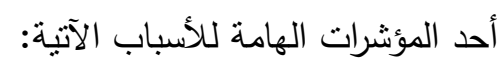

- يساعد توفير المعلومات البيئية في نوجيه أنظار الإدارة والعاملين لأهمية البعد البيئي والاجتماعي للشركات الصناعية وما يستتنج ذلك من زيادة الوعي البيئي لليهم. 
- انتتار الثركات الصناعية المتوافقة بيئياً يساعد في تحسين البيئة في دولة الكويت بصفة عامة وكذللك يساعد في إعادة صياغة أهداف تلك الثركات وإعادة ترتيب أولوياتها. - نقل خبرات الثركات المتوافقة بيئياً إلى الثركات حديثة التحول إلى الهى الاهنمام البيئي يساعد في سرعة التحول إلى الشركات الصناعية الخضراء.

\section{التراساهي المايرية}

ا -دراسة: رغدة عبد الرحمن Y Y P اهتمت الدراسة بتوضيح دور المراجعة البيئية

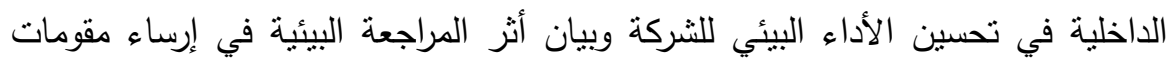

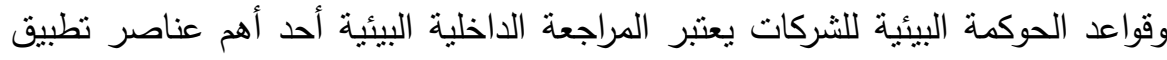
الحوكمة البيئية، تؤثر لجنة المراجعة بشكل رئيسي في ضمان أجزاء المراجعة البيئية الداخلية بما يحقق كفاءة وفعالية التقارير المالية البيئية (رغدة صلاح لئهية محمد عبد الرحمن:

r -دراسة: أياد الاجنى 1 ب ب هدفت الدراسة إلي وضع آليات محددة ومنهجه تضمن مشاركة أوسع لمجتمع الجامعة الداخلي والخارجي عند صباغة روية ورسالة الجامعة وعند تحديثها، ووضع مؤشرات أداء محددة للأهداف والأنشطة تصف الثكل النهائي المراد الوصول إليه من الهدف أو النشاط، وإجراء مراجعة دورية سنوية للخطة الاستراتيجية، من

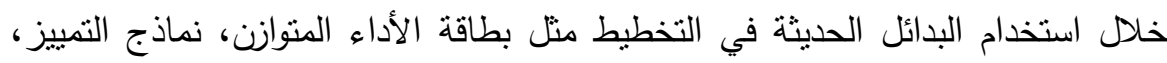

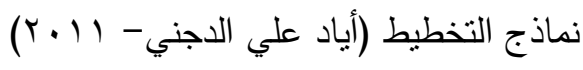

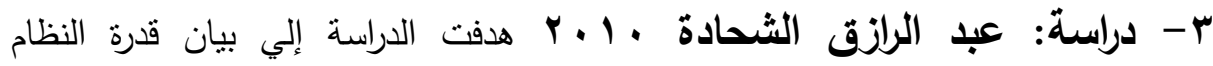
المحاسبي المطبق في الثركة السورية العامة للأسمدة على انتاج معلومات نافعة يمكن من خلالها قياس تكاليف الأداء البيئي لنشاطاتها وعلى تحليل عناصر تكاليف الأداء البيئي

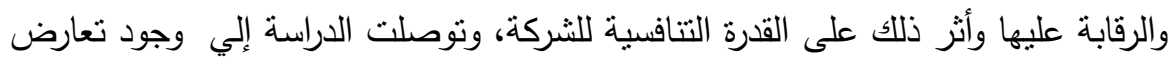
بين منطلبات حماية البيئة والاستخلال الاقتصادي الكفء لموارد الثركة، وتدنى تحقيق وجن 
الكفاءة الاقتصادية للشركة مع المحافظة على البيئة بسبب الأضرار المختلفة

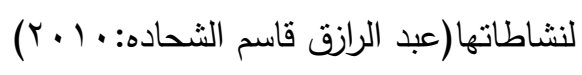

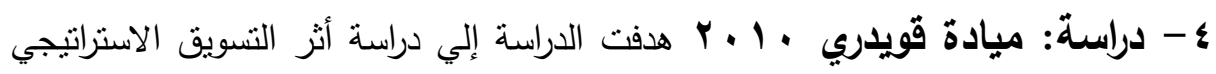

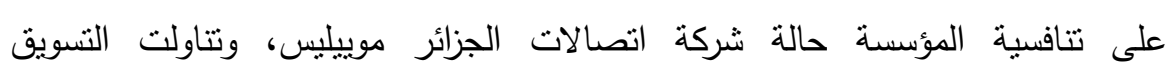
الاستراتيجي من خلال نماذج منحني الخبرة ومصفوفة BCG، جنرال الكتريك وماكنزي

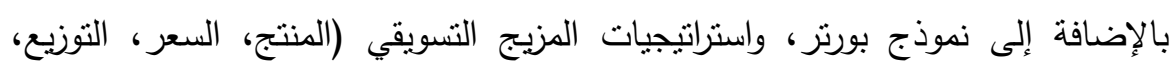

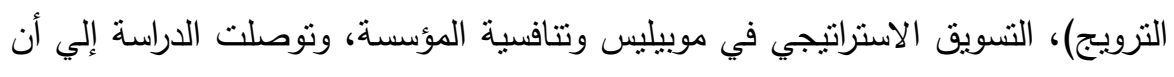
نجاح أي مؤسسة عمومية وخاصة المؤسسة موضوع البحث موبيليس تتحكم فيها أربعة

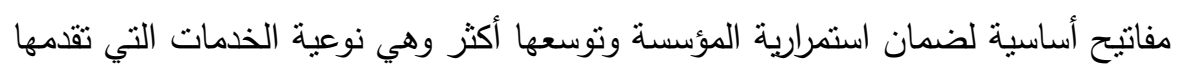
للعملاء وثانياً توسيع التغطية وثالث نوعية الثبكة بالإضافة إلى العلاقة بين المتعامل

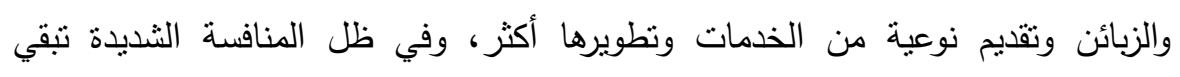
موبيليس دائما في خدمة عملاءها من خلال الاستمرار بتقديم أحسن الخدمات بأسعار

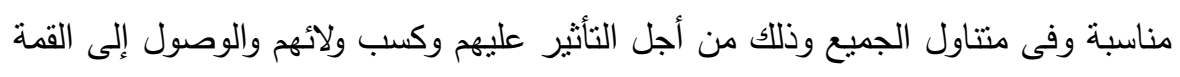

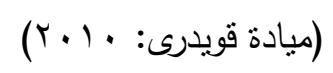

ه Seetha Raman, A., Mohamed Ismail, \& Sarayanan, A دراسة

q . . . هدفت الدراسة إلي تحليل ودراسة العلاقة بين المنظمات والبيئة زاد الاهنمام بها مؤخراً ويعتبر التباحث debate حول التغييرات العالمية المناخية والتتوع الجغرافي موضوعاً لجميع الثركات حول العالم، وبينت أن تلوث الهواء والماء والتربة تعتبر مشكلة

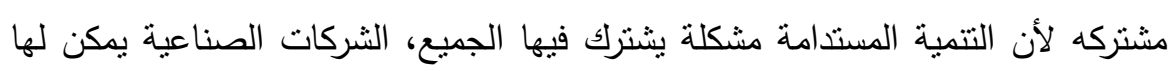
أن تؤدى دوراً حيوياً في تخفيض درجة تدهور البيئة وذلك لأن الثركات لديها موارد مالية، لتهنة

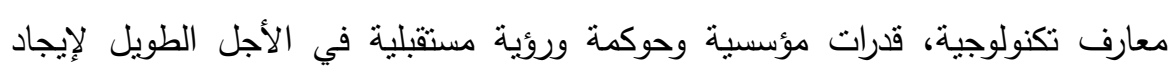
حلول بيئية مستقبلية. 


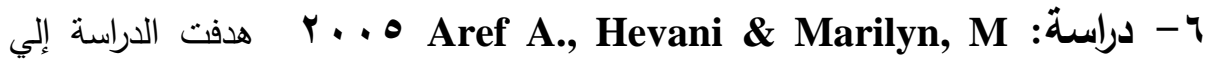
التعرف إلي إدارة وقياس الأداء، إدارة سلسلة الطلب الخضراء، ونظام قياس أداء إدارة

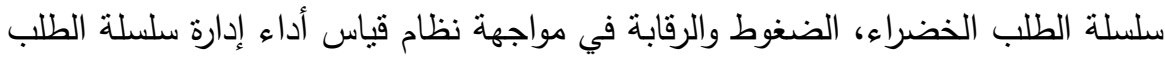
الخضراء ونظام ISO 14031 ، من خلاء مؤشرات الظروف البيئية، ومؤشرات أداء التشغيل، وإدارة مؤشرات الأداء، وتوصلت الدراسة إلي أن أدوات نظام قياس أداء إدارة

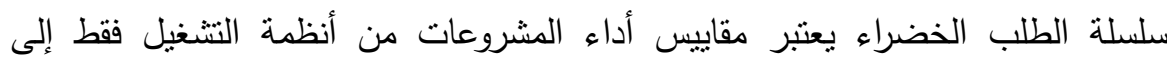

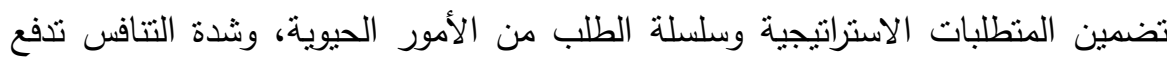
المشروعات للنظر للخارج لتحديد كيفية تحقيق واستمرار المزايا التتافية. ويتحليل الاراسات السابقة يتبين أنها اهتمت بالآتي:

- استعراض بعض نماذج الإفصاح البيئي ومقارنتها بالأداء الفعلي للشركات الصناعية.

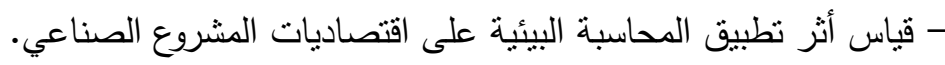

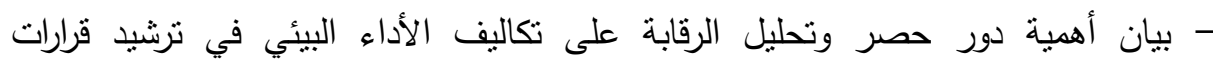
الاستثمار في برامج الإدارة البيئية ونظمها.

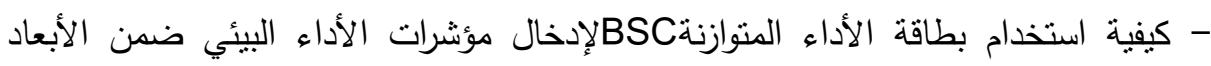
الأخرى.

- نظام قياس أداء إدارة سلسلة الطلب الخضراء وأدوات نظام القياس. - بيان قدرة النظام المحاسبي المطبق في إنتاج معلومات تساعد في قياس الأداء البيئي. - تأثنر الضغوط الخارجية والأطراف ذوب المصالح وانعكاسات ذلك على الاهتمام بالأداء البيئي. - أهمية الاعتراف بالمصروفات البيئية وأهمية قياسها. 


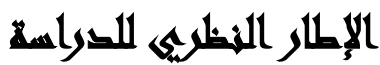

علاقة النظام المحاسبي البيئي بجودة الأداء المؤسسي: يعتبر دراسة وقياس الآثار البيئية للمشروعات المطروحة في إطار ما يعرف بالمحاسبة البيئية منمثلة في قياس الأعباء

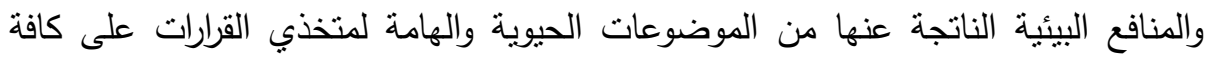

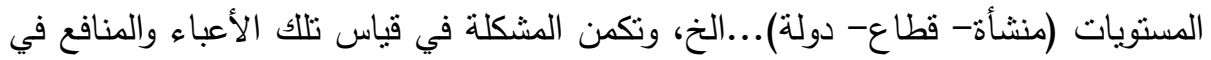

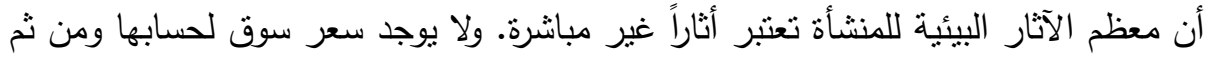

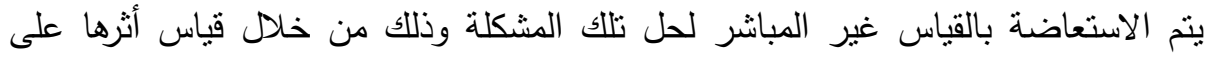
عناصر رأس المال بأثكاله المختلفة. أولاً: خطوات تطبيق المحاسبة البيئية: تمر المحاسبة البيئية في المنشآت على عدة خطوات:

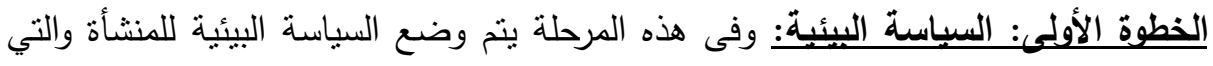

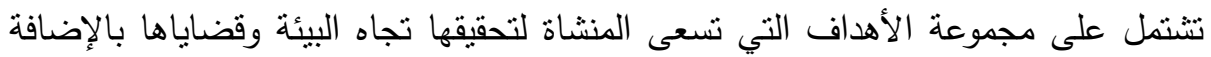
إلى التحديد الدقيق والواضح لدىى مسئولية المنثاة عن تحقيق تلاك الأهداف وكذلك تنتئمل نلك المرحلة تحديد المبالغ التي ترصدها المنشأة لتحقيق هذه الأهداف في ضواء الكئ الموازنة

الخطوة الثانبة: الخطط التفصيلية:وفى هذه المرحلة يتم إعداد الخطط الففصلة الني تساعد المنشأة في تحقيق أهدافها البيئية وقضاياها المحددة مسبقاً في المرحلة الأولى وفى تلكانك

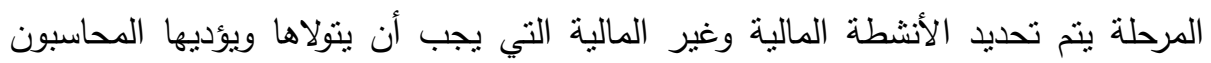
اللمحافظة على البيئة ومواردها.

الخطوة الثالثة: التنفيذ:وفى هذه المردلة ينم التنجيل والتقرير عن كافة الأنشطة الرقابية

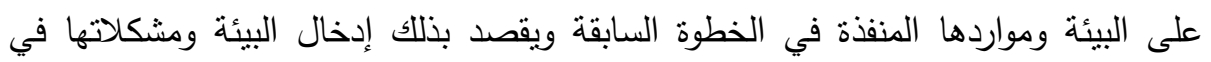
صلب العمل المحاسبي سواء من خلال إدراج المعلومات البيئية في صورتها المالية أو الكمية الئية في الثقارير المالية السنوية أو في تقارير منفصلة ملحقه بها. Gray, R., Walters, D., Bebbington, J.\& Thomson I. (2005);vol. 6 (3) pp. 211- 239) 
ثانياً: أهمية المحاسبة البيئية في استدامة التنمية بدولة الكويت: لقد تزايد الاتجاه نحو

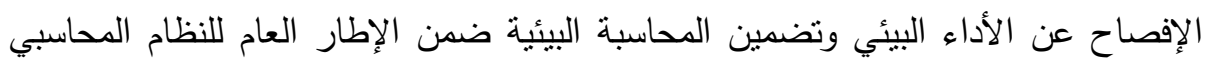
نتيجة لاهنمام المنظمات الحكومية والمجتمع المدني والهيئات الدولية والمهنية والأكاديمية الادية بالبيئة والتنمية المستخامة.

1 - أسباب الاهتمام بالمحاسبة البيئة: تلجأ معظم دول العالم للاهتمام بالمحاسبة البيئية للعديد من الأسباب منها:

- البيئة موضوع حيوي ومستمر وضرورة حمايتها وتتميتها من خلال مفهوم التتمية المستدامة.

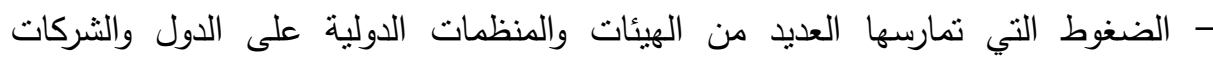
الصناعية الملوثة للبيئية.

- ضرورة توجيه اهتمام الدراسات النظرية والنطبيقية بالبيئة والمحاسبة عنها وقياس تكلفة تدهورها وأعباء إصلاحها. - حتمية المحاسبة البيئية المؤيدة بالتنشريعات الدولية والمحلية والمعايير التي تتظيمها الجهات المهنية المختصة.

r - أهداف المحاسبة البئية المستمرة: تسعى المحاسبة عن الأداء البيئية إلى تحقيق مجموعة من الغايات والأهداف منها:- تسجيل التغيرات في الحالة البيئية من خلال إعداد مجموعة مستنديه ودفترية بيئية تهدف إلى الحفاظ على البيئية وحمايتها لكل فترة مالية، وذلك بدون أدنى شك يساعد المنشأة في

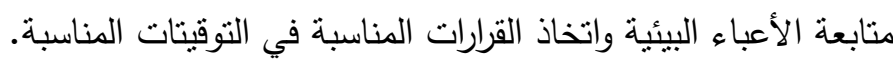
- إعداد دليل حسابات بيئي مرن يساعد على إحكام الرقابة على الأعباء والمنافع البيئية.

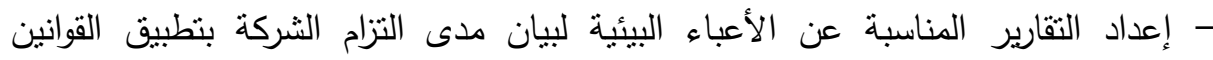
والتشريعات البيئية.

- بيان المسئولية الاجتماعية والبيئية للمنشآت لضمان الاستمرار -

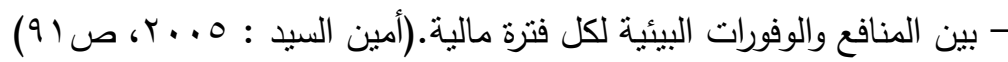




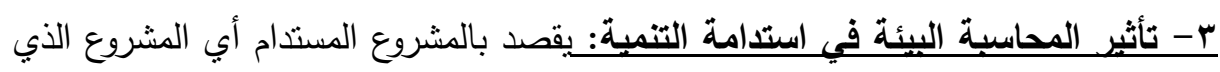
يهدف لتحقيق مستويات أداء عالية ويؤدى إلى إضافة قيمة للمستثمرين بالمشروع وللعملاء والموردين والعاملين وكافة الهيئات التي تعتمد عليها في أعماله وذلك بالتركيز على النظم

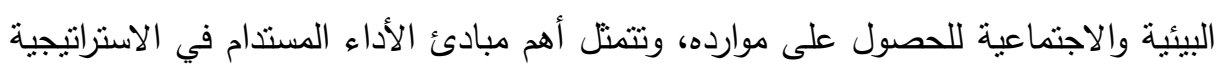

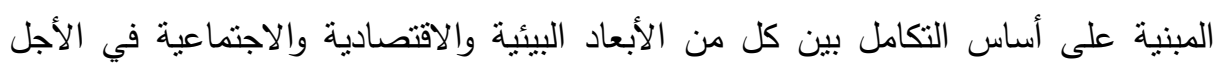
الطويل بالإضافة إلى الابتكار ، إدارة المخاطر والثفافية، ويمكن القول بأن المحاسبة المالية

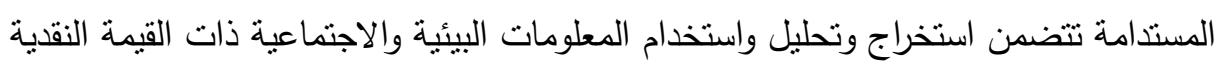
بهدف تحسين الأداء البيئي الاجتماعي الاقتصادي، ومن ثم فهي تناعد في تحقيق التكامل

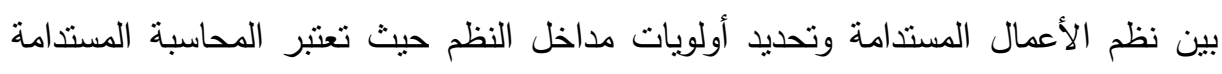

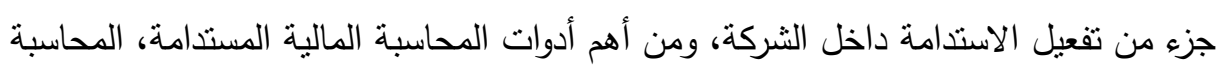

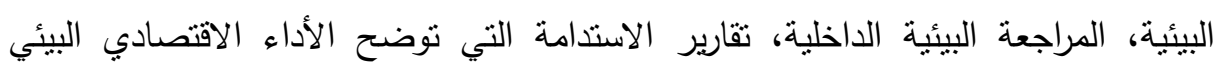

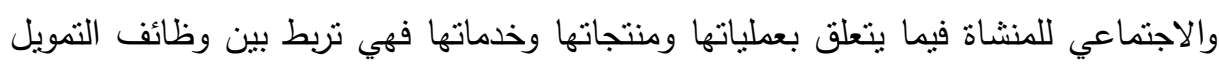

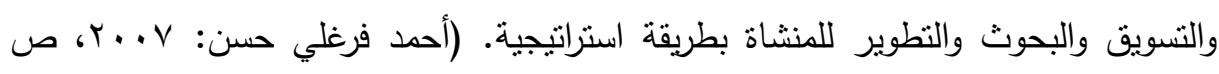

ثالثاً: استراتيجيات تحسين الأداء البيئي: تسنطيع المنشاة أن تحسن من مركزها التتافسي

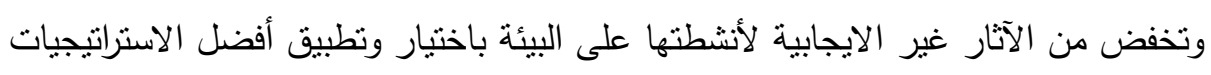

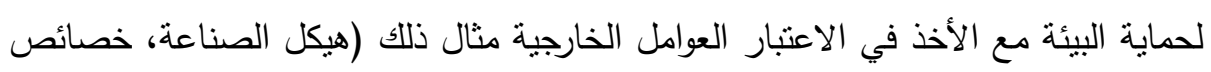

$$
\text { السوق، وغيرها). }
$$

وتتشمل استراتيجيات تحسين الأداء البيئي استراتيجية عمليات التشغيل، استراتيجية خصائص وأسواق المنتج، استراتيجية الثناملة. وفيما يلي موجز مختصر لكل نوع من أنواع لأنئين الاستراتيجيات.

1-استراتيحية عمليات التشغيل: حيث توضح هذه الاستراتيجية على فكرة مؤداها أن الميزة التكليفية يمكن أن تتحقق من تطبيق أفضل التطبيقات والممارسات التي تركز على العملية النتغيلية للمنشأة وتتضمن هذه التطبيقات: 
- إعادة تصميم عمليات الإنتاج لتكون في شكل أقل تلويثاً للبيئة. - ابتكار عمليات أقل تلويثاً. - استبدال عناصر المدخلات بأخرى أقل تلويثاً. - إعادة التدوير أو إعادة الاستخدام. ومن غير شك فإن تلك التطبيقات نساعد في خفض تكلفة الإنتاج مع زيادة كفاءة (Stead, عمليات التتغيل وخفض نكاليف المدخلات وتكاليف التخلص من المخلفات W.F. \& Stead, J.G. (2008);PP. (10-15) ب-استراتيجية خصائص أسولق المنتج: تنتمل نلك الاستراتيجية على قيام المنشأة بإعادة

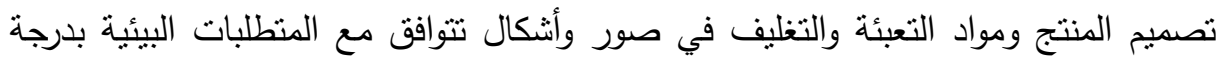
عالية، بالإضافة إلى الإعلان عن المنافع البيئية المرتبطة بتلك المنتجات مما يوجد احتمال زيادة الطلب على ذلك المنتج وبالتالي زيادة الإيرادات بالتبعية. ب-الاستراتيجية الثاملة: هذه الاستراتيجية تعتمد على كل من مدخل تحليل دورة حياة المنتج الذي يمكن تخفيض التلوث البيئي من خلال المراحل المختلفة لدورة حياة المنتج ففي مرحلة التصميم والتطوير يمكن تخفيض التلوث البيئي عن طريق تصميم منتج صديق للبيئة وآمن وتصميم عمليات إنتاجية غير ملوثه للبيئة، وفي مرحلة اختبار المورد يمكن تخفيض التلوث من خلال اختيار المورد المناسب الذي يساعد في توفير المواد والمكونات والعناصر النظيفة النية المنوافقة بيئياً وغير الملوثة للبيئة وفى مرحلة التصنيع بمكن تخفيض التلوث البيئي عن طريق لئن تخفيض الانبعاثات الضارة بالبيئة من خلال العمليات الصناعية واستخدام أجهزة ومعدات

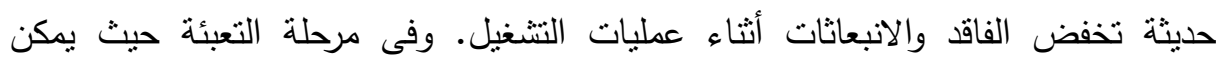
تخفيض التلوث البيئي عن طريق استخدام عبوات غير ضارة بالصحة وكذلك قابله لإعادة التدوير والاستخدام، وفى مرحلة الاستخدام يجب العمل على إلا يترتب على استخدام المنتج

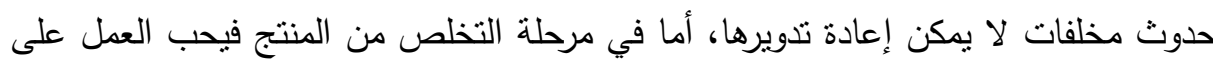

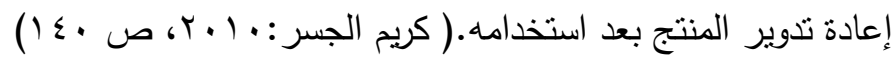




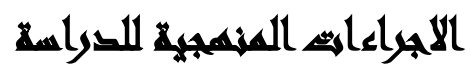

الإجراءات المنهجية للاراسة: اعتمد الباحثون علي الدنهج الاستقرائي الاستتباطي

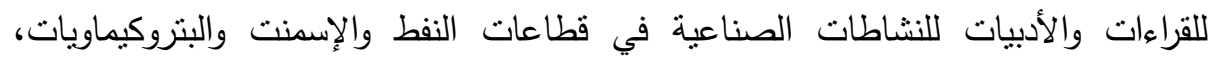

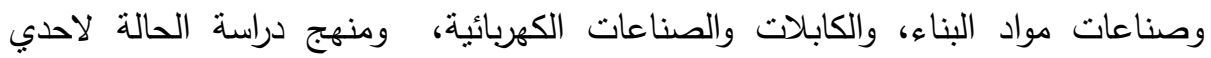
شركات صناعة الاسمنت بالكويت، من خلال تصميم قائمة استقصاء تخص الماتهات الماسبين والمراجعين والمدراء الماليين في شركة الاسمنت كإحدى الثركات الصناعية الكويتية ، وذلك الكي

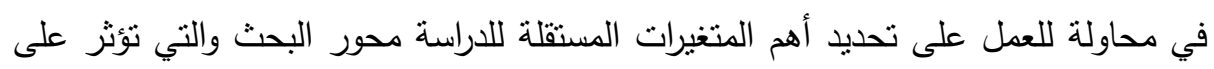

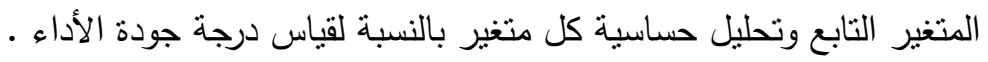
متغيرات الاراسة المتغيرات المستقة (X)

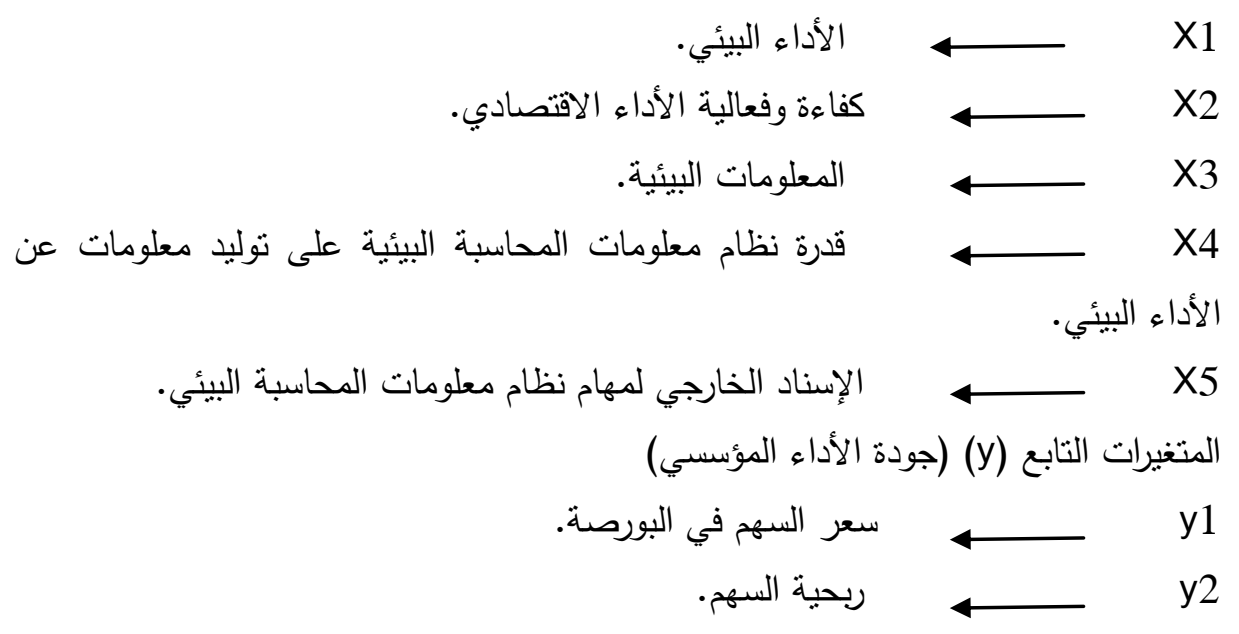




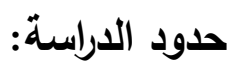

الحد الجغرافي: دولة الكويت (قطاعات النفط والإسمنت والبتروكيماويات، وصناعات مواد البناء، والكابلات والصناعات الكهربائية) باعتبارها من الصناعات الملوثة للبيئة. الد البشري: عينة من المدراء الماليين ومسئولي البيئة في الثركات الصناعية في قطاعات النفط والإسمنت والبتروكيماويات، وصناعات مواد البناء، والكابلات والصناعات الكهربائية، وكذلك أساتذة الجامعات المتخصصين في مجال البيئة.

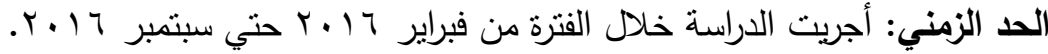
عينة الاراسة وخصائصها: قام الباحثون بجمع بيانات الدراسة من عينة بلغت سب من من مجتمع الدراسة، وقد استخدموا المعادلة التالية في تحديد حجم العينة:-

$$
\mathrm{n}=\frac{\mathrm{z}^{2} \mathrm{pq}}{\mathrm{D}^{2}}
$$

$$
\begin{aligned}
& \mathrm{n}=\frac{1.96^{2}(0.5)(0.5)}{0.05^{2}}=385 \\
& \mathbf{n}^{*}=\frac{\mathbf{3 8 5}}{\mathbf{1}+\frac{\mathbf{3 8 5}}{\mathbf{5 3 0}}}=\mathbf{2 2 3}
\end{aligned}
$$

n

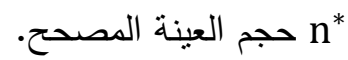

Z: الدرجة المعيارية المقابلة لمعامل الثقة 90 وهي تساوي 97 و, 1. P q (1): - نسبة الظاهرة في المجتمع). D: نسبة الخطأ المسموح به، في حدود 0\% تثنير البيانات الثخصية للعاملين بالثركة إلى النوع، وفئة العمر، والمؤهل العلمي، فئات سنوات الخبرة، وفئات سنوات الخدمة في الوظيفة الحالية. 


\section{وصف أداة الدراسة: تثتنل قائمة الاستقصاء على خمسة محاور :}

المحور الأول: ماهية تقييم الأداء البيئي، ويقيس مدى إدراك عينة البحث لماهية تقييم الأداء

$$
\text { البيئية، ويشتمل على عشر عبارات. }
$$

المحور الثاني: مشكلات القياس والإفصاح عن الأعباء البيئية، ويقيس المشكلات التي

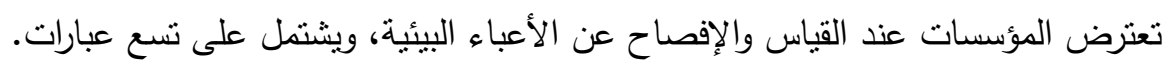

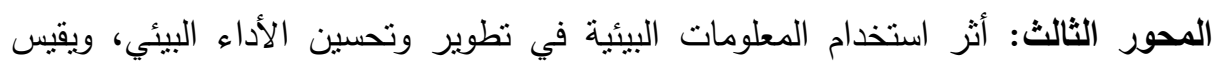

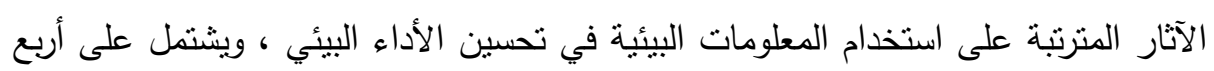
عبارات.

المحور الرابع: الإطار الفكري لنظام معلومات المحاسبة البيئية، ويشتنل على سبع عبارات. المحور الخامس: جودة الأداء المؤسسي، ويشتمل على المقاييس والمؤشرات الدالة على جودة الأداء المؤسسي.

- قام الباحثُن بعرض قائمتي الاستقصاء على المختصين لتحكيمها، وأخذ الموافقة على توزيعها واستخدامها في جمع بيانات الدراسة.

- قام الباحثّن بالاختبار القبلي Pre test لقوائم الاستقصاء، وذلك بتوزيعهات على بعلى عينة

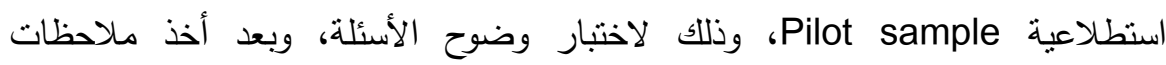

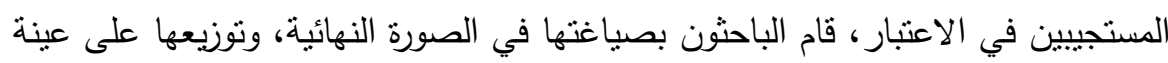

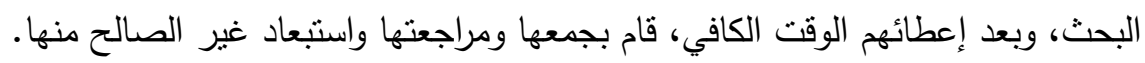

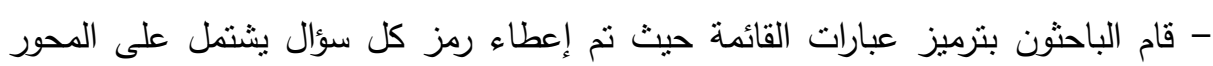

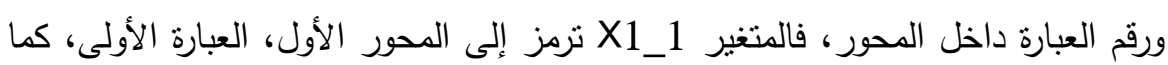
تم ترميز عبارات المتغير التابع بالرموز متغير والرمز الذي أعطى له في قائمة بملحق مخرجات البرنامج الإحصائي، لكي يتم

$$
\text { الرجوع إليه عند الحاجة. }
$$

- قام الباحثون بإعطاء أوزان للاستجابات تدل على درجة الموافقة وفقاً لمقياس ليكرت

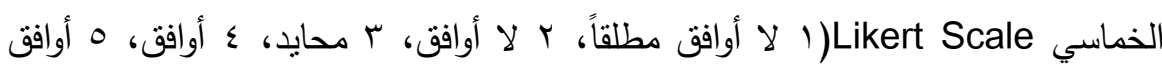


ولما كان مدى هذه الاستجابات (0-1=\{) بتوزيع على 0 فئات، فيكون طول الفئة

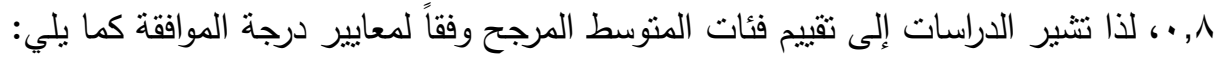

\begin{tabular}{|c|c|c|c|c|}
\hline آوافق بشدة & أوافق & محايا & لا أوافق & لا أوفق مطظقا \\
\hline $0, \ldots-\varepsilon, Y$. & $\varepsilon, 19-\uparrow, \varepsilon$. & $r, r q-r, \tau$. & $r, 09-1, \wedge$. & $1, \vee 9-1, \ldots$ \\
\hline
\end{tabular}

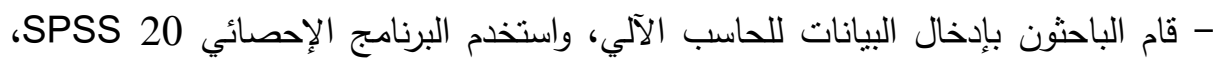

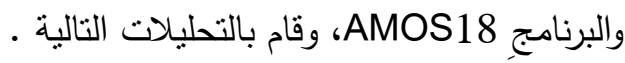

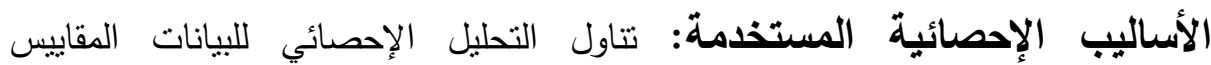

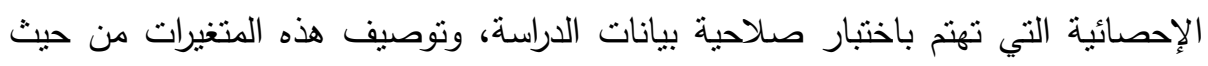

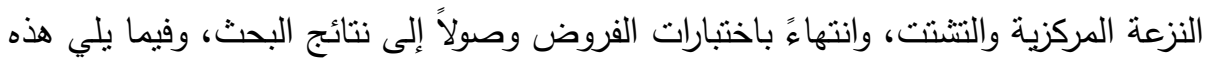
المقاييس: - مقياس الاعتمادية Reliability: وذللك من خلال المقياس (ألفا) Cronbatch Alpha:

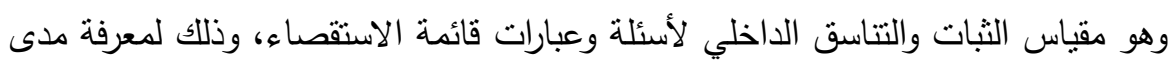
الوثوقية فى استجابات عينة البحث على أسئلة قائمة الاستقصاء، ومدى إمكانية تعميم نتائجها على مجتمع الدراسة. - العرض الجدولي والبياني للبيانات Frequency Tables \& Cahrts:وذلك عن طريق لكاتئ التكرارات والنسب المئوية حيث يبين هذا الأسلوب أعداد استجابات عينة البحث على أسئلة قائمة الاستقصاء، والأوزان النسبية لكل استجابة.

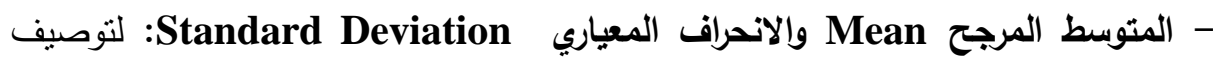
متغيرات الدراسة من حيث النزعة المركزية والتتنت - إجراء|ختبار T.Test، وقد نطلب ذلك تحديد القيمة الاختيارية والتي تمثلت في متوسطات القيم وهى ب ، وفى ضوء ذلك تم صياغة فرض العدم والفرض البديل ، كما يلي : القرض العدم : 3 : الفرض البديل : 3 > 
وتكون قاعدة الحكم بناء على مستوى المعنوية المحسوب، إذا كان أقل من ه.,. . ،

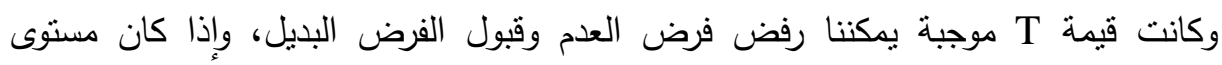

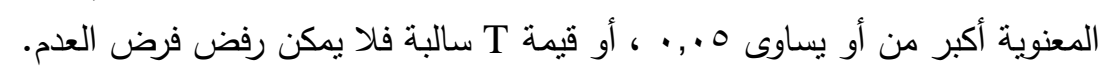

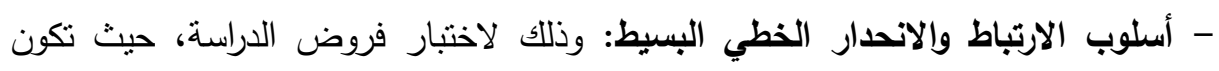

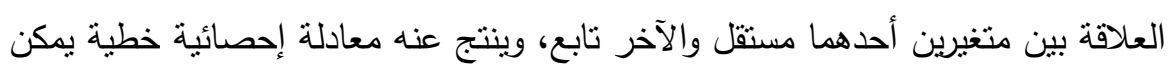

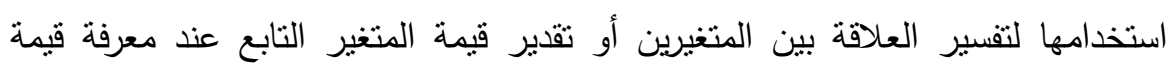

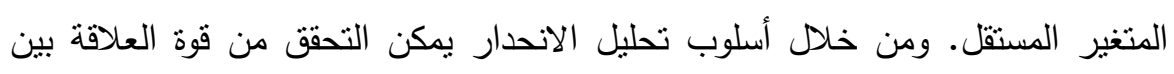
متغيرين أحدها مستقل والآخر تابع باستخدام معامل الارتباط ومعامل التحديد.

$$
\text { ومن أهم الأساليب المستخدمة في تحليل الانحدار ما يلي: }
$$

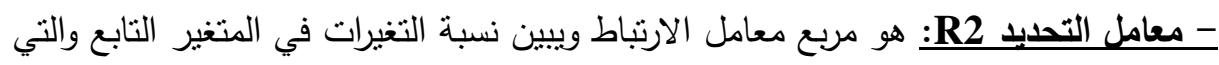
يقوم بتفسيرها وشرحها المتغير المستقل، أي يبين مدى دقة خط الانحدار في تقدير المتغير التابع باستخدام المتغير المستقل. - اختبار (F test): هو أحد أساليب تحليل التباين Analysis of Variance (ANOVA) ويختبر معنوية نموذج الانحدار ككل، ونعتمد في الحكم على مستوى المعنوية، فإذا كان أقل

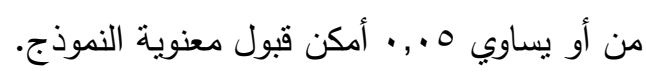

- اختبار (T test): وذلك لاختبار معنوية المعلمات المقدرة (اي ثابت الانحدار ، ومعلمة هودية

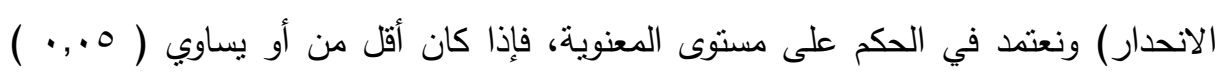
أمكن قبول معنوية المعالم المقدرة.

- تحليل المسار Path Analysis: وذلك لاختبار العلاقة بين المتغيرات حين يكون بعض المتغيرات مفسراً وتابعاً في نفس الوقت. وفيما يلي تطبيق هذه الأساليب على متغيرات الدراسة: - مقياس ثبات وصدق المحتوى لمتغيرات الدراسة : نم قياس ثنات المحتوى لمتغيرات

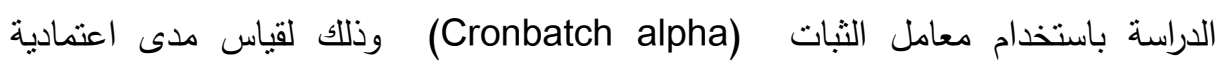
Reliability

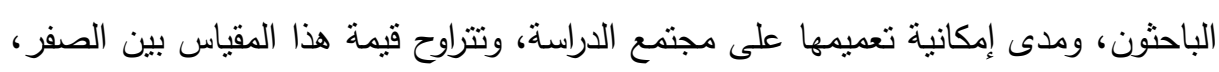

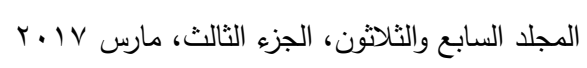


• . 1، وإذا زاد هذه المقياس عن • ج أمكن الاعتماد على نتائج الدراسة، وفيما يلي تطبيق هذا المقياس على محاور الدراسة:

جدول(ץ): اختبار الاعتمادية لمحاور الدراسة.

\begin{tabular}{|c|c|c|c|}
\hline الصدامل & معامل & العبارات & 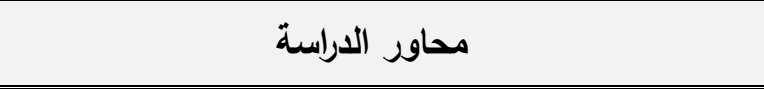 \\
\hline$\cdot, 9 \vee 0$ &., 901 & $1 \leqslant$ & ماهية تقييم الآداء البيئي. \\
\hline$\cdot, 9 \cdot 1$ & $\cdot, \wedge Y \varepsilon$ & 17 & مشكلات القياس والإفصاح عن الأعباء البيئية. \\
\hline$\cdot, \Lambda Y \wedge$ & $\cdot, 7 \wedge 0$ & $\varepsilon$ & أثز استخدام المعلومات البيئية في تحسين وتطوير الأداء البيئي. \\
\hline$\cdot, \vee \vee 9 \leq$ & $\cdot, 7 \mu \cdot$ & 11 & الإطار الفكري لنظم معلومات المحاسبة البيئية. \\
\hline$\cdot, 9 \vee \leq$ & $\cdot, 9 \leq 1$ & 14 & جودة الأداء المؤسسىى \\
\hline
\end{tabular}

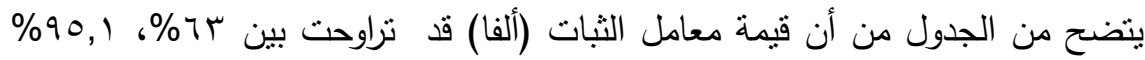

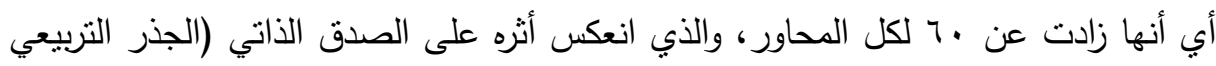

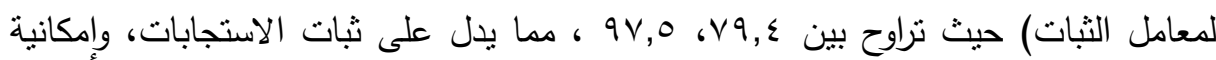
تعميم النتائج على مجتمع الدراسة.

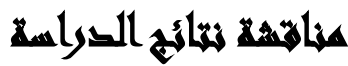

جدول(r): نتائج اختبار One Sample T test لمشكلات القياس والإفصاح عن الأعباء

\begin{tabular}{|c|c|c|c|c|c|}
\hline المعنوية & T test & معياري & نسبط وسابي & حسابي & المتغيرات \\
\hline$\cdots$ & $\varepsilon$, & $1, r 4 \lambda$ & TV,r & דוr & 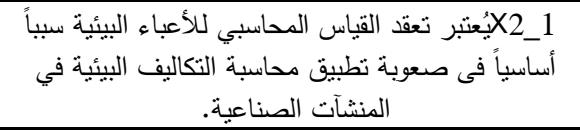 \\
\hline$\cdot, \cdots$ & $19, \varepsilon$ & $9 \leqslant 9$. & $\wedge \varepsilon, \vee$ & $\varepsilon, r$ & 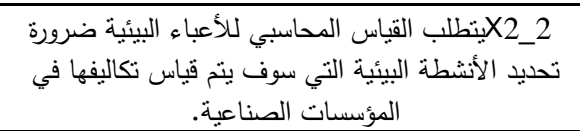 \\
\hline 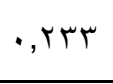 & $1, r$ & $1, \varepsilon 0 V$ & Tr, & r, Ir & 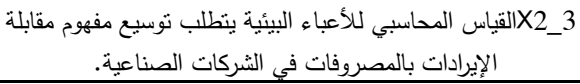 \\
\hline$\cdot, \cdots$ & $\wedge, 1$ & $1, r \vee 7$ & $V r, \Lambda$ & r, 79 & تسجيل الأعباء البيئية في سجلات واضحة. \\
\hline$\cdot, \cdots$ & $r$ r, & $\Lambda \leftrightarrow \Lambda$. & $\wedge\urcorner, r$ & $\varepsilon, r_{1}$ & وجود معايير محددة يتم استخدامها فى عملية القياس. \\
\hline
\end{tabular}


تابع جدول(ץ):

\begin{tabular}{|c|c|c|c|c|c|}
\hline مستوى & $T$ test & معياري & نسبط وسب & حسابي & المتغيرات \\
\hline$\cdot, \cdots$ & 17,0 & $1, \cdots 1$ & $\wedge r, l$ & $\varepsilon, 1$. & 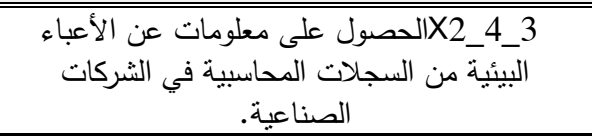 \\
\hline$\cdot, \cdots$ & $1 \cdot, \varepsilon-$ & $1, \cdot \wedge \varepsilon$ & $\varepsilon \varepsilon, \wedge$ & $r, r \varepsilon$ & الإساءة إلى سمعة الثركات الصناعية. \\
\hline$\cdot, \cdots$ & $14,9-$ & $\cdot, 9 \vee \wedge$ & $\varepsilon 1, \wedge$ & $r, .9$ & 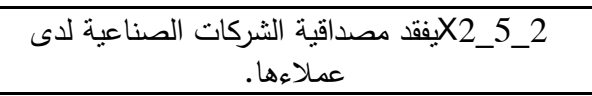 \\
\hline$\cdot, \cdots$ & $M, V$ & $1,17 \varepsilon$ & $\vee q, \vee$ & ५, १९ & 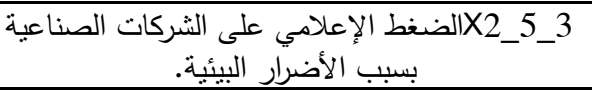 \\
\hline$\cdot, \cdots$ & Ir, & $1, \cdot r r$ & $\leqslant 1, \wedge$ & $r, .9$ & 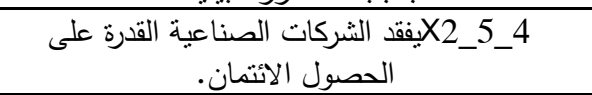 \\
\hline$\cdot, \cdots$ & $1 \cdot, \varepsilon$ & $1, Y \wedge \uparrow$ & $\vee \vee, \Lambda$ & ґ,^৭ & 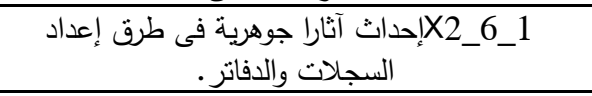 \\
\hline$\cdot, \cdots$ & $0,0-$ & 1, ror & $0 ., \mathrm{V}$ & $r, 0 \leqslant$ & 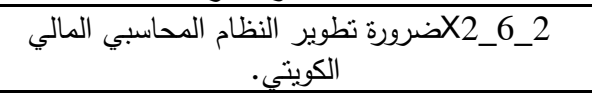 \\
\hline$\cdot, \cdots$ & $1 r, 7-$ & 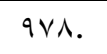 & $\varepsilon r, r$ & $r, 11$ & X2_6_323 الإدارة بسبب عدم ضمان النتائج. \\
\hline$\cdot, \cdots$ & 7,1 & $1, \varepsilon \cdot r$ & $\vee 1, \varepsilon$ & r,ov & 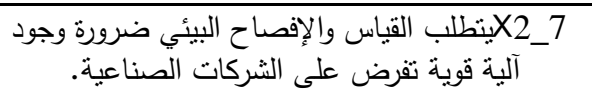 \\
\hline$\cdot, V \leq V$ & $\cdot, r-$ & $1, \leqslant 0$. & $09, \varepsilon$ & r, १V & 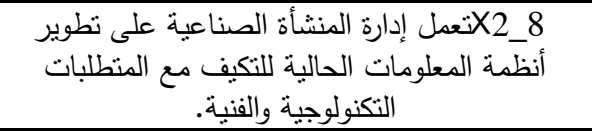 \\
\hline$\cdot, \cdots$ & $1 \wedge, \wedge$ & 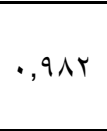 & $\wedge \varepsilon, \vee$ & L, & 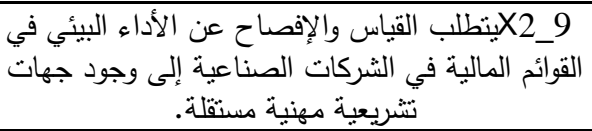 \\
\hline
\end{tabular}

- يتضح من الجدول أن مشاكل القياس والإفصاح عن الأعباء البيئية تمثلت العبارات التي

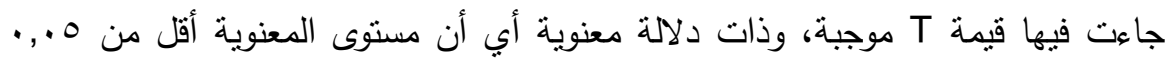

$$
\text { وهذه العبارات هي : }
$$

- (وجود معايير محددة ينم استخدامها في عملية القياس، ينطلب القياس المحاسبي للأعباء البيئية ضرورة تحديد الأنشطة البيئية التي سوف ينت قياس تكاليفها في المؤسسات

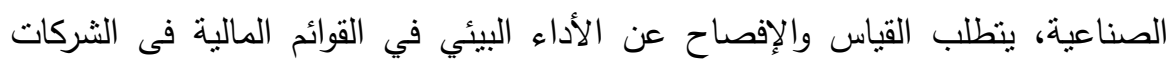
الصناعية إلى وجود جهات نشريعية مهنية مستقلة، الحصول على معلومات عن الأعباء

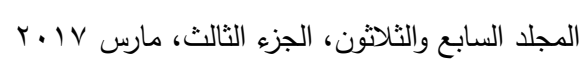


البيئية من السجلات المحاسبية في الثركات الصناعية، الضغط الإعلامي على الثركات الصناعية بسبب الأضرار البيئية، إحداث آثنارا جوهرية في طرق إعداد السجلات والدفاتر ، تسجيل الأعباء البيئية فى سجلات واضحة، ينطلب القياس والإفصاح البيئي ضرورة وجود آلية قوية تفرض على الثركات الصناعية، يُعتبر تعقد القياس المحاسبي للأعباء البيئية

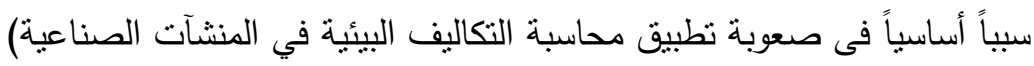

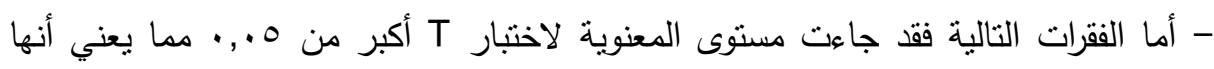
تعتبر محايدة أي أنها لا تشكل مشكلات:

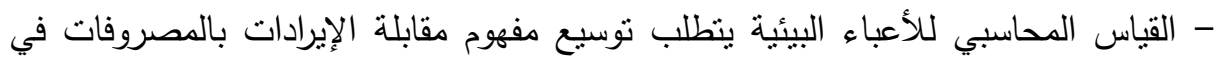

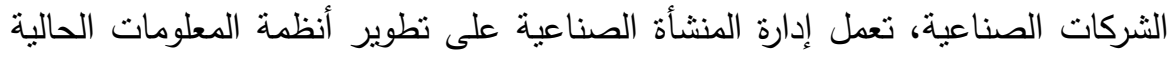
للتكيف مع المتطلبات التكنولوجية والفنية).

- والفقرات التالية لم توافق عليها عينة البحث حيث كانت قيمة T سالبة وذات دلالة معنوية: - (ضرورة تطوير النظام المحاسبي المالي الكويتي، الإساءة إلى سمعة الثركات الصناعية، تخوف الإدارة بسبب عدم ضمان النتائج، يفقد مصداقية الثركات الصناعية لاى عملاءها، يفقد الثركات الصناعية القدرة على الحصول الائتمان) مما يعني أن الإفصاح عن الأعباء البيئية لا يؤدي إطلاقاً إلى هذه الآثار .

- تحليل المسار Path Analysis: يمكن اعتبار أن وجود نظام معلومات بيئية بؤثز على جودة الأداء المؤسسي بطريق مباشر، وبطريق غير مباشر عن طريق تأثيره على الأداء البيئي، الذي يؤثر بدوره على جودة الأداء المؤسسي، لذا بعتبر الأداء البيئي

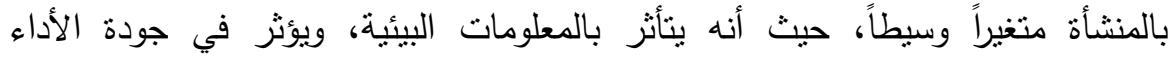
المؤسسي، كما يؤثر الإطار الفكري لنظم معلومات المحاسبة البيئية على الأداء البيئي أيضاً، والتحليل المناسب في هذه الحالة هو تحليل المسار Path Analysis. 
جدول(؛): الآثار المباشرة وغير المباشرة لاستخدام نظام معلومات المحاسبة البيئية على جودة

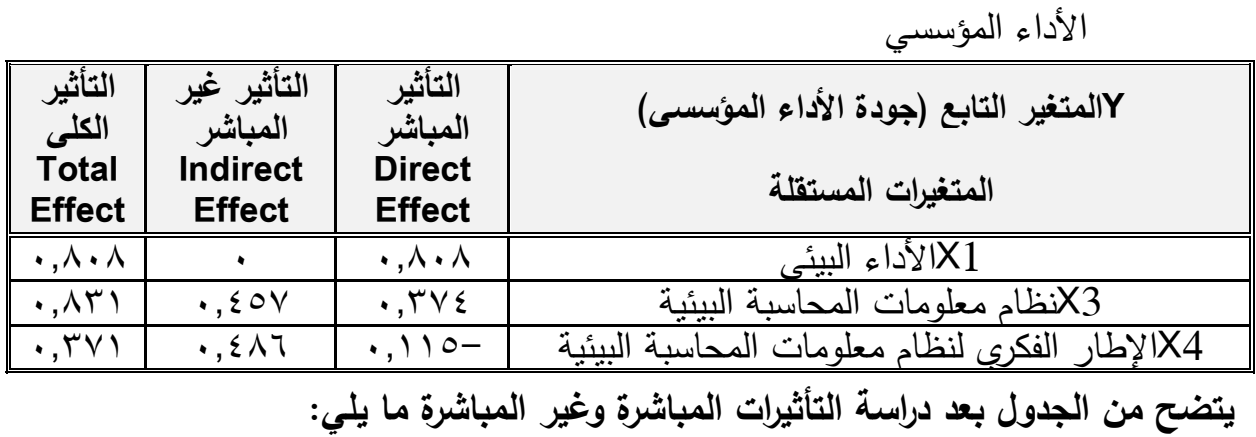

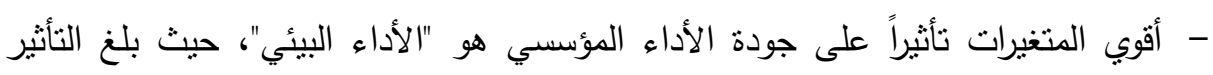

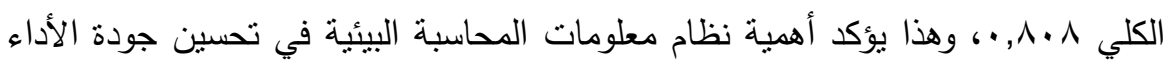

- يلي ذلك في التأثير "نظام معلومات المحاسبة البيئية" حيث بلغ التأثير الكلي اسمرئ.

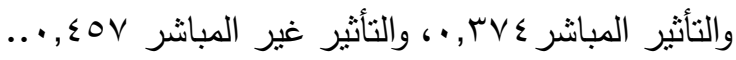

- وفي الترتيب الثالث "الإطار الفكري لنظام معلومات المحاسبة البيئية" حيث بلغ التير التأثنير

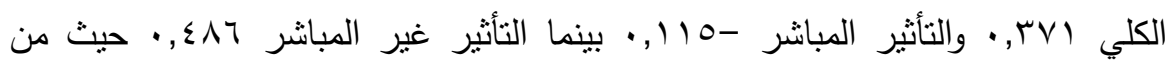

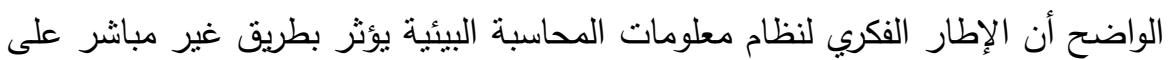
جودة الأداء المؤسسي، أما التأثير المباشر فقدام ثبتت عدم معنوياته أي أنه بساوي صفراً.

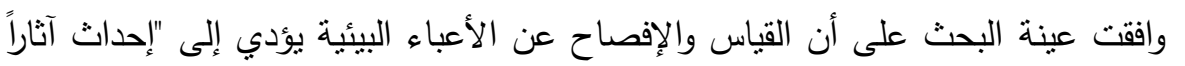
جوهرية في طرق إعداد السجلات والدفاتر"، ولم توافق على كلٍ من: "تخوف الإدارة بسبب الإسب الطباه عدم ضمان النتائج"، و "ضرورة تطوير النظام المحاسبي المالي الكويتي".

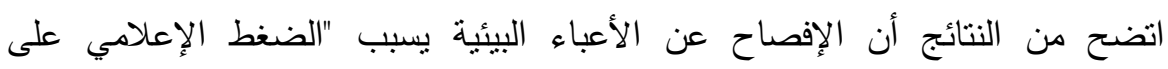

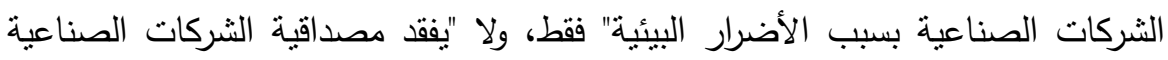

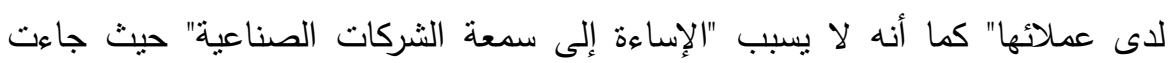

$$
\text { استجابات عينة البحث بعدم الموافقة. }
$$

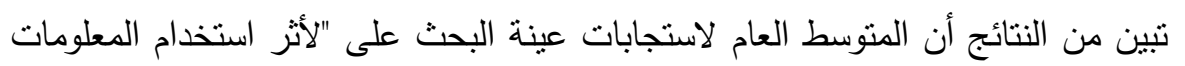

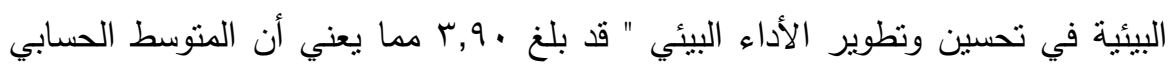

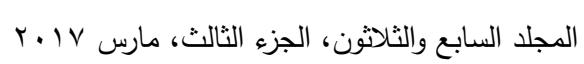


النسبي قد بلغ م \% مما يدل على اتجاه استجابات عينة البحث نحو الموافقة، الأمر

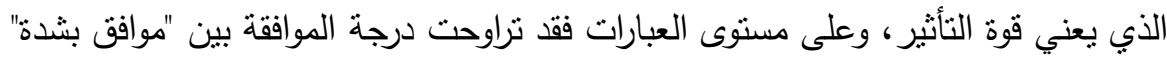

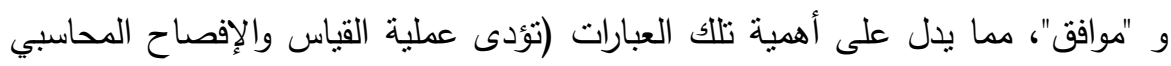
للأعباء البيئية في القطاع الصناعي الكويتي إلى تلبية احتياجات المستهلكين بالمنتجات

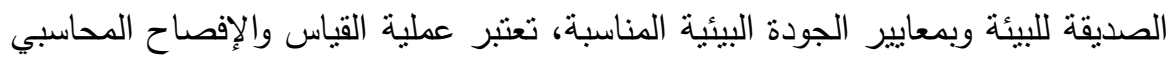

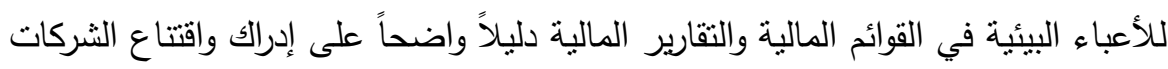
الصناعية بقضايا البيئة الحرجة، تؤدى عملية القياس والإفصاح البيئي إلى تقييم الأداء البيئي وتحسينه في الثركات الصناعية من خلال القرارات التى يتم اتخاذها، تؤدى عملية

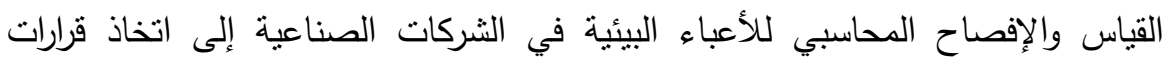
تحسين الأداء البيئي وترشيدها باعتبارها جزءاً مكملاً لنظم الإدارة البيئية). •ُعتبر إمداد الإدارة بالمعلومات ذات التتوع والتي يوفرها نظام معلومات المحاسبة البيئية مصدراً لتشجيع مديري التشغيل محل الاهتمام. • استخدام تكنولوجيا المعلومات يؤثز على عمليات التشغيل حيث يؤدى إلى تغير التهير الاستراتيجيات التي تتبناها إدارة المنشأة مما يؤدى إلى تحسين الأدياء

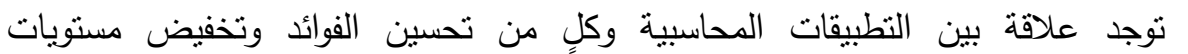
التكاليف. الاعتبارات التي تؤثر على نظام معلومات المحاسبة البيئية بالترتيب (متغيرات اقتصادية، متغيرات وعوامل بيئية، متغيرات قانونية ومهنية، متغيرات وعوامل تتظيمية، تكنولوجيا المعلومات، متغيرات وعوامل سلوكية). تشمل أبعاد الأداء المؤسسي أداء الأفراد، أداء المنشأة في إطار السياسات العامة لها، بالإضافة إلى أداء المنشأة في إطار كلٍ من البيئة الاقتصادية والاجتماعية النقافية.

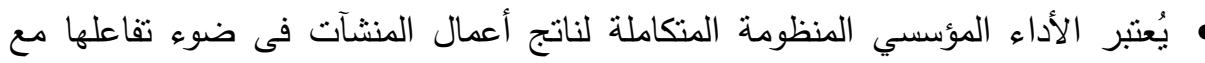
عناصر بيئتها الداخلية والخارجية. 
تشتنل جودة الأداء المؤسسي على مجموعة من العناصر منها الربحية والإنتاجية وكفاءة التشغيل.

تتنتمل المؤشرات المالية والمؤشرات غير المالية وقياس الأصول الملموسة وغير الملموسة بالإضافة إلى الجوانب العريضة للأداء المؤسسي على الاستراتيجيات والعمليات والموارد البشرية اللازمة

تتنتمل خطوات تحسين الأداء على تحليل الأداء باختبار أداء المنشأة ضمن أولوياتها وقدراتها، وذللك يتطلب تحليل الوضع الراهن والمتوقع للمشكلات في أداء العمل والمنافسة. هُعرف الأداء بأنه إنجاز الأهداف التتظيمية باستخدام الموارد المتاحة بكفاءة وفعالية.

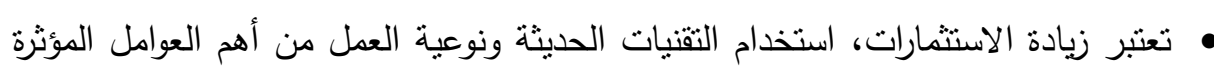
في زيادة الإنتاجية. هقتضى الأداء المؤسسي التركيز على العناصر الفريدة التي تميز المنشأة عن غيرها من المنشآت. هؤدي تطبيق إدارة الجودة الثشاملة إلى (زيادة معدلات رضا العملاء، انخفاض التكاليف

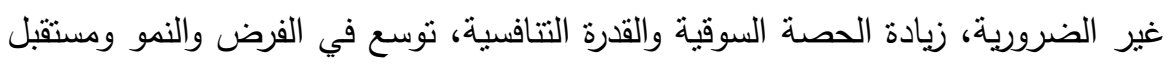
أكثر استمراراً للمنشأة على المدى البعيد، زيادة الكفاءة الإنتاجية للعاملين)

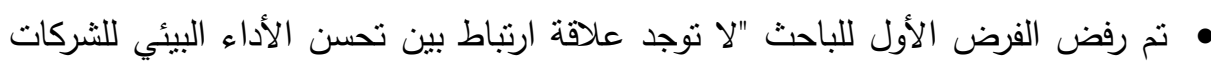

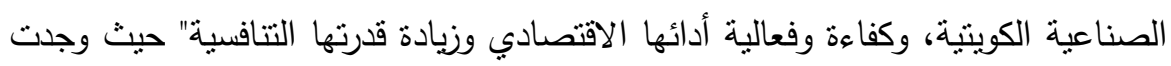

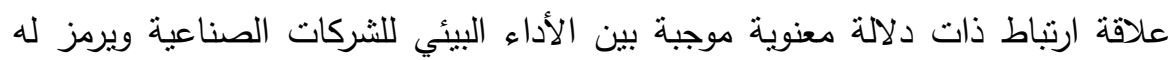

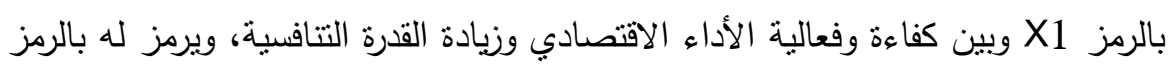
Y =0.031 +0.993*X1 + كما أمكن بناء نموذج انحدار أخذ الصيغة التالية: Y eحيث:Yتمثل "كفاءة وفعالية الأداء الاقتصادي وزيادة القدرة التتافسية"، X1 تمثل "الأداء

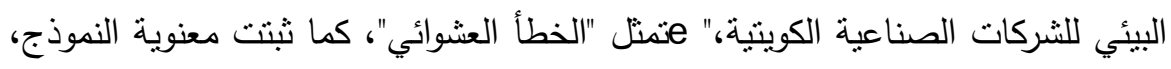

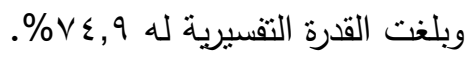
• م رفض الفرض الثاني للباحث "لا توجد علاقة ارتباط بين وجود نظام معلومات محاسبة بيئية له القدرة على التحليل والرقابة والتقرير عن الأداء البيئي، وترشيد وتحسين الأداء 
البيئي في الثركات الصناعية الكويتية" حيث وجدت علاقة ارتباط ذات دلالة معنوية

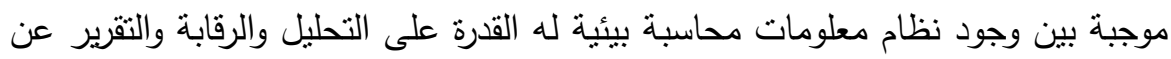
الأداء البيئي ويرمز له بالرمز X3 وبين ترشيد وتحسين الأداء البيئي في الثركات

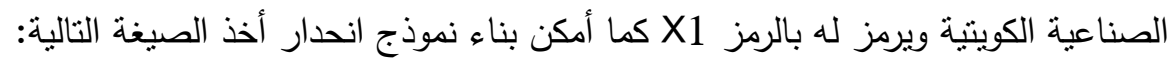

$$
\varepsilon X 1=-0.028+0.967 * \text { X3 }+
$$

حيث:"X1 نرشيد وتحسين الأداء البيئي في الشركات الصناعية، " X3 "وجود نظام

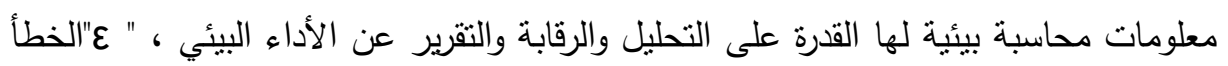

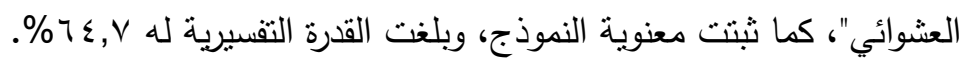

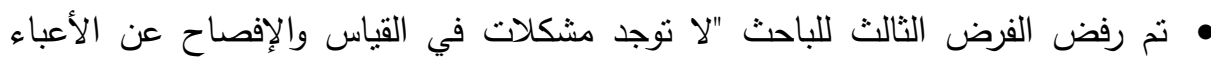
البيئية"، حيث وجدت عدة مشاكل تمثلت في (وجود معايير محددة يتم استخدامها في عملية القياس، يتطلب القياس المحاسبي للأعباء البيئية ضرورة تحديد الأنشطة البيئية التي في فئي سوف يتم قياس تكاليفها في المؤسسات الصناعية، يتطلب القياس والإفصاح عن الأداء

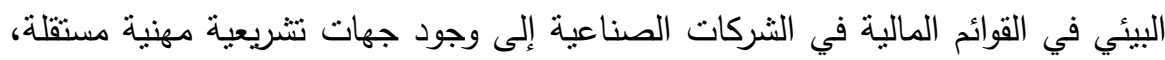
الحصول على معلومات عن الأعباء البيئية من السجلات المحاسبية في الثركات الصناعية، الضغط الإعلامي على الثركات الصناعية بسبب الأضرار البيئية، إحداث

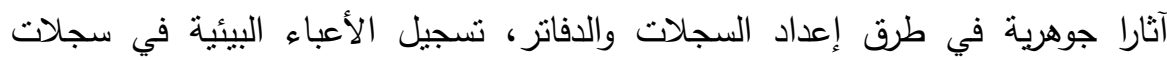
واضحة، يتطلب القياس والإفصاح البيئي ضرورة وجود آلية قوية تفرض على إعلى الشركات

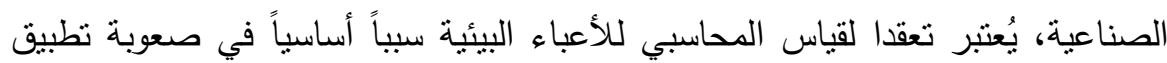

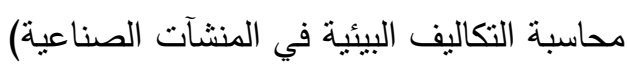

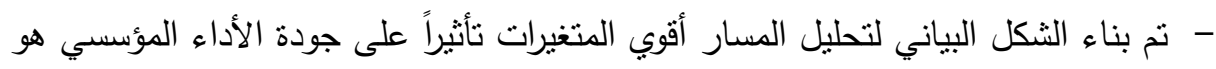

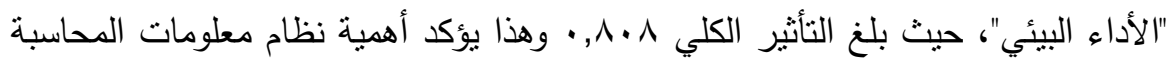
البيئية في تحسين جودة الأداء المؤسسي، يلي ذلك في التأثثر "نظام معلومات المحاسبة التئية

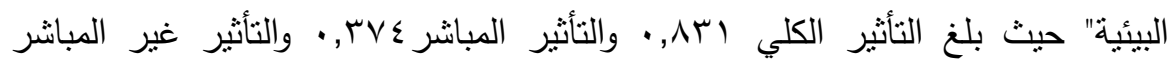

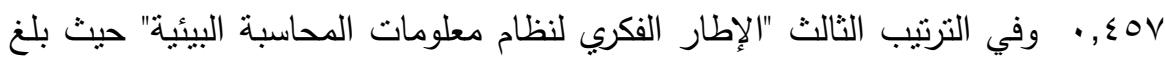




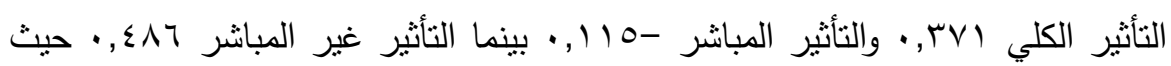

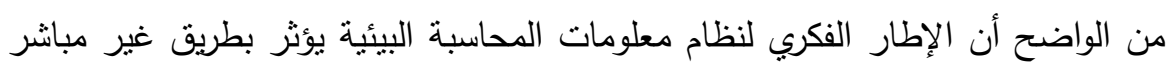

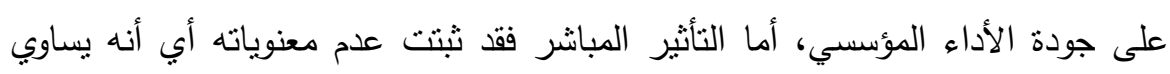
صفراً.

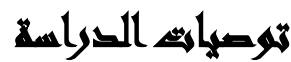

$$
\text { في ضوء نتائج الاراسة يوصى الباحث بما يلي: }
$$

ا-لتحديد وزيادة منفعة المعلومات التي يوفرها نظام المحاسبة البيئية المطبق في الشركات

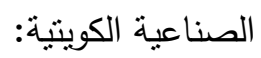

- بذل العناية الكافية لتحديد ونوضيح العلاقة السبيية بين التصرف المخالف للبيئة والضرر

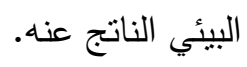

- تسعير المنتجات بصورة سليمة وذلك باختيار أساليب إنتاجية رشيدة وصديقة للبيئة

$$
\text { والتعريف والتوصيف القانوني للمخلفات السامة. }
$$

r-فيما يتعلق بمواجهه أوجه القصور في المعلومات التي يوفرها نظام معلومات المحاسبة البيئية المطبقة في الثركات الصناعية الكويتية:

- زيادة الاهتمام بالبيئة والمحافظة عليها بعد النطور الكبير الذي حدث في تقنيات الصناعة وما سبيته المشروعات من تلوث للبيئة نتيجة قيامها بالتخلص من مخلفات التتغيل.

$$
\text { - التحديد الواضح والدقيق للأهداف البيئية. }
$$

- وضع نظامًا محددًا للمساعلة البيئية.

- التكامل بين الجهود المختلفة المتخصصة والضرورية للمحاسبة البيائية.

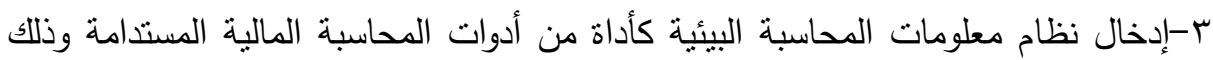
للربط بين وظائف التمويل والتسويق والبحوث والتطوير للمنشأة بصورة استراتيجية.

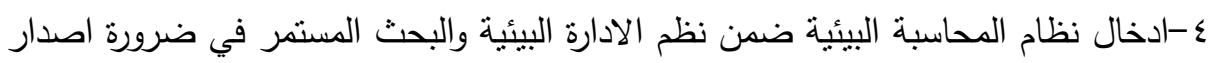
معايير للمحاسبة البيئية لتنظيم الاجراءات المحاسبية المتعلقة بالبيئة ومشكلاتها. 


\section{المرالئ2}

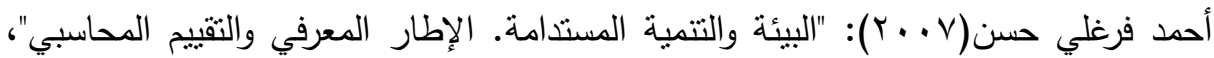
مركز تطوير الدراسات العليا والبحوث، جامعة القاهرة.

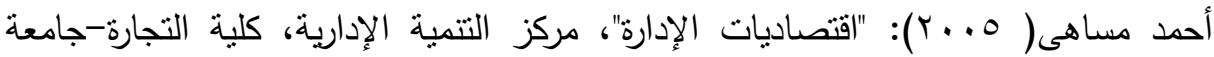

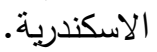

أمين السيد أحمد لطفي(0 . . ؟): "المراجعة البيئية"، الدار الجامعية، الإسكندرية.

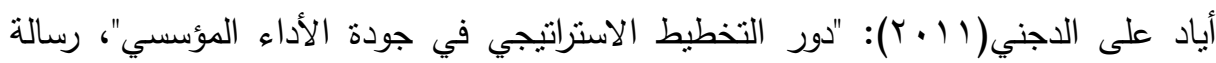
دكتوراه غير منشورة، كلية التربية، جامعة دمثنق.

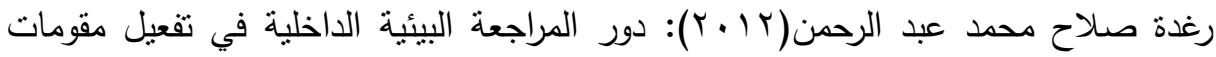

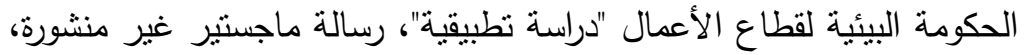
كلية التجارة، جامعة القاهرة.

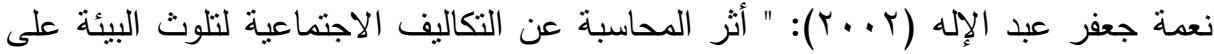

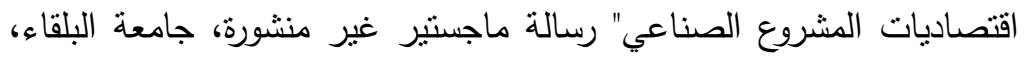

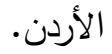

عبد الرازق قاسم الثحادة (• ( ب): القياس المحاسبي لتكاليف الأداء البيئي للشركة السورية

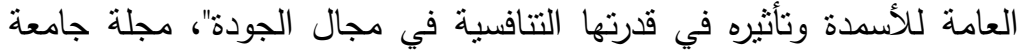

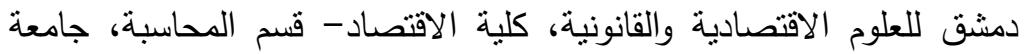

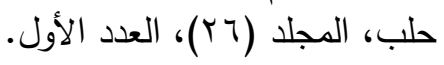

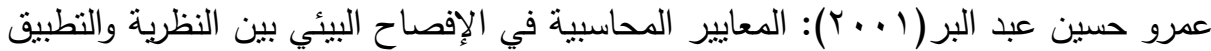

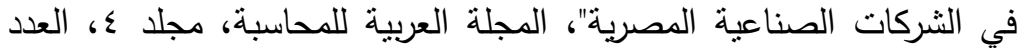

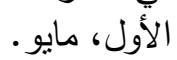

عيسى محمد الغزالي(؟ . . ץ): "السياسات البيئية جسر التتمية"، المعهد العربي للتخطيط

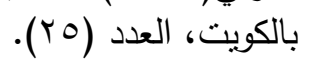

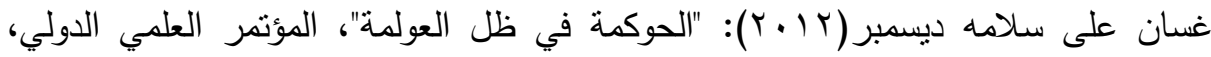

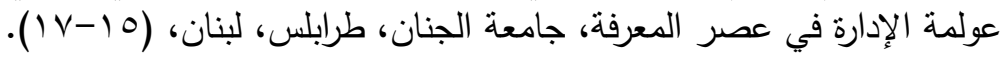

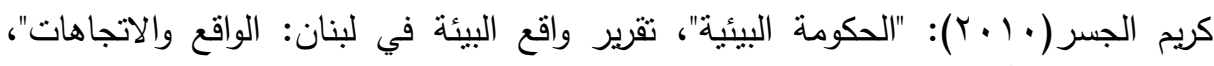

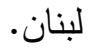


ميادة قويدي( • ( ؟ ): أثز التسويق الاستراتيجي على نتافسية المؤسسة- دراسة حالة مؤسسة

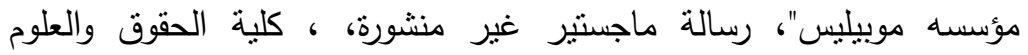
الاقتصادية، جامعة قاصدي مرباح ، الجزائر .

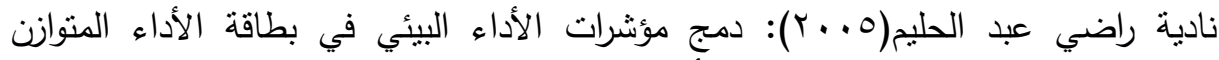

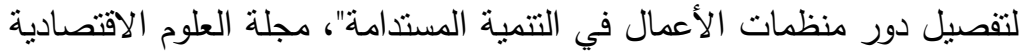

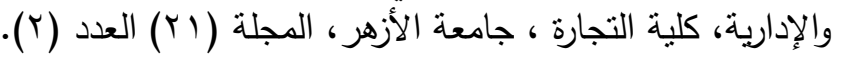

Aref A., Hevani \& Marilyn, M ;(2005),Performance Measurement for green supply chain management, Helms Benchmarking An International Journal, vol. 12 No. 4.

Gray, R., Walters, D., Bebbington, J.\& Thomson I. (2005): "The greening of Enterprise An Exploration of the Non role of environmental accounting and environmental Accountatants in Organizotionat change critical perspective in accounting", vol. 6 (3) pp. 211- 239.

Seetha Raman, A., Mohamed Ismail, \& Sarayanan, A;(2009), Environmental accounting as a tool for environmental management system", it is available at: www.bioline. Org.br/Ja.

Stead, W.F. \& Stead, J.G. (1998):"An Empitical investigation of sustainability strategy implementation in industrial organization IND". Collins and M. Stark PP. (10-15).

Stead, W.F. \& Stead, J.G. (2008):"An Empitical investigation of sustainability strategy implementation in industrial organization IND". Collins and M. Stark PP. (10-15).

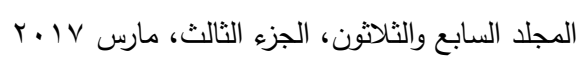




\title{
MEASURING IMPACT OF USING \\ ENVIRONMENTAL ACCOUNTING INFORMATION \\ SYSTEM ON INSTITUTIONAL QUALITY OF \\ PERFORMANCE \\ A CASE STUDY ON ONE OF THE INDUSTRIAL COMPANIES \\ IN KUWAIT STATE
}

\author{
Khatab, G. S. ${ }^{(1)}$; Khalifa, M. A. ${ }^{(1)}$; Al-Ajmy, R. S. ${ }^{(2)}$
} and Hamad, H. M.

1) Faculty of Commerce, Ain Shams University 2) Faculty of Administration science, Kuwait University

\begin{abstract}
The study aimed to show the extent of the contribution of information and environmental accounting in the Kuwaiti industrial companies in the special environmental performance, cost analysis and control, and the statement of the relationship between the environmental performance of industrial companies with Kuwaiti and efficiency of economic performance, effectiveness and competitiveness in the market, the researchers relied on inductive deductive, and the case study method by designing questionnaires concerning accountants, auditors and managers millions in cement company as one of the Kuwaiti industrial companies, applied on a sample number 223 of CFOs and officials of the environment in industrial companies in the oil, cement and petrochemical sectors, and building materials industries, cables and electrical industries, the study found out that there are correlation significant positive significant between the environmental performance of industrial companies and the efficiency and effectiveness of economic performance and increase competitiveness,
\end{abstract}

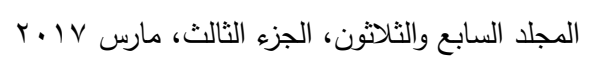


and the existence of significant positive significant correlation between the presence of environmental accounting information system has the ability to analyze, control and report on environmental performance and the rationalization and improvement of environmental performance in industrial companies Kuwait, the study recommended increasing concern for the environment and maintain after the great development that has occurred in the manufacturing techniques. 